\title{
CONSTRUINDO HEGEMONIA: democracia e livre mercado (atuação do NED e do CIPE na América Latina) ${ }^{1}$
}

\author{
Ary Cesar Minella*
}

\begin{abstract}
A partir da constatação da existência de conexões entre as associações de representação de classe dos bancos na América Latina, que se denominou rede transassociativa, o trabalho analisa a conexão dessa rede com organizações constituídas nos Estados Unidos para atuar politicamente ao redor do mundo. O foco é o Center for International Private Interprise (CIPE), constituído em 1983, vinculado à Câmara de Comércio dos Estados Unidos, e que promove reformas políticas e econômicas orientadas para o mercado. É uma das quatro organizações centrais do National Endowement for Democracy (NED), entidade financiada pelo governo daquele país. Examina-se especialmente o caso da Argentina e do Peru. Constata-se como a relação dessas entidades com organizações latino-americanas constitui uma base estrutural para o processo de construção de hegemonia de caráter neoliberal e como se articula com o sistema financeiro. O procedimento metodológico inclui a pesquisa bibliográfica e documental.

PALAVRAS-CHAVE: hegemonia, democracia, sistema financeiro, redes transassociativas, National Endowement for Democracy (NED), Center for International Private Interprise (CIPE).
\end{abstract}

\section{INTRODUÇÃO}

"Democracia é...”. A partir de setembro de 2008, os internautas que acessam o YouTube, o conhecido site de vídeo, foram chamados a definir esse termo tão presente no debate contemporâneo. Os melhores vídeos serão contemplados com uma viagem a Washington e com outras mordomias. Os promotores do desafio são a Agência Americana para o Desenvolvimento Internacional

* Doutor em Estudos Latino-americanos pela Universidad Nacional Autónoma de México. Mestre em Sociologia pela Universidade Federal do Rio Grande do Sul. Professor titular da Universidade Federal de Santa Catarina. Departamento de Sociologia e Ciência Política. Campus Trindade. Cep: 88.040-900 - Florianópolis - Santa Catarina - Brasil.minella@matrix.com.br

${ }^{1}$ Trabalho desenvolvido dentro do projeto América Latina: uma visão sociopolítica das transformações e das perspectivas do sistema financeiro (IV etapa), iniciado em março de 2008, com apoio do Conselho Nacional de Desenvolvimento Científico e Tecnológico (CNPq), junto ao Núcleo de Estudos Sociopolíticos do Sistema Financeiro (NESFI). Agradeço especialmente a colaboração de Laura Gomez, que atua com Bolsa Permanência da UFSC e também a colaboração dos estudantes do Curso de Ciências Sociais que optaram por realizar a disciplina de Prática de Pesquisa junto a esse projeto: no primeiro semestre de 2008, Leonardo Salles e Gabriela Augusta da Silva, que atualmente participa como bolsista de IC do CNPq, e alunos do semestre 2008/2, especialmente Álvaro Pereira Santos.
(United States Agency for International Development - USAID), subordinada ao Departamento de Estado, e uma organização chamada Fundo Nacional para a Democracia (National Endowment for Democracy-NED).

O que tem em comum essa "simpática" promoção com o Instituto Apoyo no Peru, ou com o Centro de Implementación de Políticas Públicas para la Equidad y el Crecimiento (CIPPEC) na Argentina? Ou ainda com o Instituto Brasileiro de Governança Corporativa (IBGC) e o Centro de Divulgación del Conocimiento Económico para la Libertad (CEDICE) da Venezuela? Mais ainda: o que isso tem a ver com o tema que nos ocupa aqui? As respostas a essas perguntas dependem, a meu ver, do entendimento do que representam o NED e as organizações a ele associadas. A pesquisa que realizo atualmente chegou ao NED através do Centro Internacional para a Empresa Privada (CIPECenter for International Private Enterprise) e a esse a partir da análise das associações de bancos na América Latina.

Uma das constatações centrais dessa análise foi identificar oque denominei de rede transassociativa 
das associações de bancos, constituída a partir da presença simultânea de uma mesma instituição financeira na direção de associações de bancos de diferentes países (Minela, 2007). Bancos ou grupos financeiros norte-americanos e europeus apresentam maior centralidade nessa rede, como, por exemplo, o Citibank, que, em 2006, ocupava 13 postos de direção em 10 países, e os espanhóis Santander e Bilbao Vizcaya, ambos presentes na direção de associações em sete países. Esses bancos desenvolvem uma ativa política de participação nas entidades de classe do setor financeiro. A partir de uma perspectiva que procura analisar as conexões das associações de classe do empresariado (e especialmente das empresas e grupos econômicos que as comandam) com outras formas de organização, dirigi a pesquisa para as organizações genericamente definidas como político-ideológicas. Um exemplo importante era oferecido pelos Institutos Liberais fundados no Brasil nos anos 1980, mantidos por grandes empresas brasileiras e multinacionais, incluindo grupos financeiros, $e$ que foram amplamente analisados nas obras de Gros $(2003,2004)$. Nesse rastreamento, identifiquei o CIPE, uma organização norte-americana que apoia ações políticas e ideológicas dos empresários na América Latina e em outras partes do mundo.

Este artigo apresenta os primeiros resultados da pesquisa e tem um caráter nitidamente exploratório-descritivo que, segundo avalio, socializa com o leitor bases empíricas, o que permite ampliar elementos interpretativos presentes nas análises sobre a realidade latino-americana contemporânea. Analiso, em primeiro lugar, o NED, depois o CIPE, seguido de um primeiro levantamento sobre o modo como o sistema financeiro inserese nas redes de organizações a elas vinculadas. Finalmente, elaboro reflexões preliminares sobre o significado dessas articulações.

\section{O CONTEXTO GLOBAL. REARTICULAÇÃO DA AÇÃO DO GOVERNO E DAS CORPORAÇÕES NORTE-AMERICANAS: a criação do National Endowment for Democracy (NED)}

Ao final dos anos 70 e início dos 80, conforme mostram vários estudos, o governo dos Estados Unidos redefiniu parte de sua estratégia de atuação e intervenção no exterior. O contexto global inclui um questionamento interno e externo das operações da Agência de Inteligência Americana (CIA), as implicações das ditaduras apoiadas na América Latina e as transformações que se operavam na economia capitalista. Além do poder executivo, o legislativo americano e as corporações privadas foram envolvidos nesse processo.

Quando, finalmente, em 1983, o governo Reagan e o Congresso dos Estados Unidos aprovaram a formação do NED, estavam institucionalizando, através de uma organização não governamental, mas sustentada com recursos governamentais, um dos canais fundamentais de sua atuação e intervenção no exterior. ${ }^{2}$ Uma peça fundamental na construção de uma hegemonia que se caracterizou como neoliberal, mas que é, sobretudo, uma tentativa de atender à reestruturação capitalista em curso, conforme os interesses estratégicos do governo e das corporações norte-americanas.

A formação do NED foi seguida pela criação do Center for International Private Enterprise (CIPE), e a ele também se vincularam o National Democratic Institute for International Affairs (NDI) e o National Republican Institute for International Affairs, mais tarde denominado International Republican Institute (IRI). Também se filiou ao NED o Free Trade Union Institute (FTUI), um dos institutos criados pela American Federation of Labor Congress of Industrial Organizations (AFL-CIO) para atuar no exterior (Lowe, 2008; Ospina, 2007). ${ }^{3}$

\footnotetext{
${ }^{2}$ A história do NED, a partir de sua própria perspectiva, aparece em artigo de Lowe (2008).

${ }^{3}$ Para mais detalhes sobre a formação do NED, além dos documentos dessa instituição, incluindo o artigo de Lowe (2008), ver Ospina (2007), Hale (2003), Guilhot (2001), Scott e Walters (2000). O texto de Ospina, publicado no Le Monde Diplomatique (edição brasileira) é uma boa síntese e contribui para o entendimento do contexto do surgimento do NED e da sua atuação política.
} 
Ary Cesar Minella

O NDI e o IRI ${ }^{4}$ são institutos associados ao Partido Democrata e ao Partido Republicano respectivamente; o CIPE constituiu-se como uma entidade da U.S. Chamber of Commerce (Câmara Americana de Comércio), uma poderosa organização empresarial à qual se vinculam mais de uma centena de associações empresariais no mundo, incluindo a maioria dos países latino-americanos. Em 1997, a AFL-CIO unificou seus quatro institutos de atuação no exterior, incluindo o FTUI, criando o American Center for International Labor Solidarity (ACILS), também conhecido como Solidarity Center. ${ }^{5}$ A estrutura do NED representa, assim, uma articulação estratégica entre o Estado americano, os dois partidos políticos dominantes, as corporações norte-americanas e a cúpula do movimento sindical.

De acordo com Lowe, os objetivos do NED, definidos em sua fundação, são

... encorajar o desenvolvimento de instituições democráticas através de iniciativas do setor privado; facilitar o intercambio entre grupos do setor privado (especialmente entre os quatro institutos integrados ao NED) e os grupos democráticos no exterior; promover a participação não-governamental em programas de treinamento democrático; fortalecer os processos democráticos no exterior em cooperação com as forcas democráticas locais; promover a cooperaçã̃o entre o setor privado dos Estados Unidos e aqueles no exterior "dedicados aos valores culturais, instituições, e organizações democráticas pluralistas"; e encorajar o desenvolvimento democrático consistente com os interesses dos Estados Unidos e dos grupos que recebem a assistência. (2008)

O mesmo autor - que, aliás, é vice-presidente do NED - destaca que a formalização dessa

\footnotetext{
${ }^{4}$ Em 2005, junto com outras organizações, o IRI organizou, no Congresso Nacional brasileiro, um seminário sobre reforma política no país. $\mathrm{O}$ evento foi analisado recentemente pela imprensa, pois o candidato republicano John McCain é um dos altos diretivos do Instituto (ver a matéria "Os EUA tentaram influenciar a reforma política do Brasil”, publicada pela Folha de São Paulo, 22 jul., 2008, p.A10).

${ }^{5}$ Para sua atuação no exterior, além do Free Trade Union Institute (FTUI), criado em 1977 para atuar na Europa, especialmente na Espanha e Portugal, a AFL-CIO contava com o American Institute for Free Labor Development (AIFLD - criado em 1962 para operar na América Latina), o African-American Labor Center (AALC, 1964) e o Asian-American Free Labor Institute (AAFLI, 1968) (cf. Amorim, 2007, p.354. Esse autor faz uma detalhada análise da fusão desses institutos para a formação do Solidarity Center e sua atuação no Brasil).
}

instituição como uma organização não-governamental, apesar de ser financiada pelo governo dos Estados Unidos, “... permite que ela possa apoiar forças políticas democráticas em situações repressivas ou politicamente sensíveis, onde o apoio do Governo dos Estados Unidos [...] pode ser diplomática ou politicamente inviável.” (Lowe, 2008, p. 8). Como observam Scott e Walters (2000, p. 255), o NED permite desenvolver políticas que normalmente seriam impedidas por princípios de soberania e não-intervenção, e essa "diplomacia informal” é um elemento potencialmente útil para a política externa. Essa dimensão intervencionista foi denunciada no próprio Congresso norte-americano desde o início da formação do NED.

ONED é uma organização juridicamente privada, mas seu orçamento está presente no Departamento de Estado e deve ser aprovado pelo Congresso norte-americano. Os recursos são repassados basicamente pela USAID. Durante os anos 90, recebeu entre 30 e 35 milhões de dólares anualmente, parte dos quais é operada diretamente pelo NED (entre 40-45\%), e a outra é repassada para as quatro organizações, que também recebem fundos de outras fontes, como as corporações privadas (Scott; Walters, 2000, p. 239). Os recursos são utilizados para financiar atividades e organizações de diversos tipos no exterior: centros de pesquisa e formulação de políticas públicas (conhecidos como think tanks), ONGs, associações empresariais e de trabalhadores, partidos políticos, organizações diversas da sociedade civil. ${ }^{6}$ Ao mesmo tempo, contribui para o processo de "onguização" da política social, conforme menciona Oliveira (2006, p. 284), e articula-se com o conjunto de forças que interferem nas políticas públicas. Na avaliação de Petras (1997, 1999), um conjunto de ONGs, criado ao longo dos anos 80 e 90, desenvolveu uma ação política para minar o crescimento de movimentos

${ }^{6}$ Entre 1990 e 1997, o NED financiou diretamente 1.754 programas no mundo, com um total de US\$ 153,2 milhões de dólares. Esses recursos foram assim distribuídos: organizacões da sociedade civil, 28,6\%; organizacões de trabalhadores, $28,5 \%$; partidos políticos, $16 \%$; instituições educacionais, 15,4\%; organizações empresariais, 5,3\%; mídia, 5,8\%; governamentais, 0,3\% (Scott; Walters, 2000, p. 243, 244). 
sociais que se opunham ao modelo neoliberal.

O NED recebe fundos específicos para apoiar iniciativas em "países com interesse especial", como ocorreu com Polônia (Sindicato Solidariedade), Chile, Nicarágua, países do Leste Europeu, África do Sul, Mianmar (antiga Birmânia), China, Tibet, Coreia do Norte. Depois dos atentados de 11 de setembro de 2001, fundos especiais foram dirigidos para os países com significativa população mulçumana no Oriente Médio, África e Ásia Central (Lowe, 2008). Segundo estimativas oficiais do NED, cada dólar investido nos programas no exterior gera fundos adicionais equivalentes a oitenta centavos provenientes de outras fontes, como ONGs, fundações privadas e organizações governamentais (Scott; Walters, 2000, p. 254). Uma das principais iniciativas do NED foi a criação do World Movement for Democracy, que articula pessoas e organizações que apoiam a democracia ao redor do mundo. ${ }^{7}$

No período de 1990 a 1997, os recursos para a América Latina representaram 14,9\% dos fundos totais canalizados diretamente pelo NED, e os países prioritários foram Nicarágua, Cuba, México, Guatemala, Chile e Argentina. No México, foram viabilizados 21 programas, com recursos equivalentes a US\$ 2,2 milhões (Scott; Walters, 2000, p. 245, 248, 252). Em 2006, quando vários países do continente latino-americano realizaram eleições presidenciais e legislativas (Brasil, Chile, Colômbia, Costa Rica, Equador, Haiti, México, Nicarágua, Peru e Venezuela), o NED financiava 95 projetos em 11 países, incluindo 14 projetos regionais. Mais de um terço dos projetos se dirigiu à região subandina (Bolívia, Colômbia, Equador, Peru e Venezuela), com o maior número deles concentrados na Venezuela. Nesse país, o NED financiou atividades de organizações locais relacionadas com a independência e a transparência do poder judiciário, os direitos humanos, a defesa da independência da sociedade civil e com organizações indígenas, "fortalecendo suas habilidades e enco-

${ }^{7}$ Esse movimento já realizou quatro assembleias mundiais: Nova Delhi 1999, São Paulo 2000, Durban 2004, Istambul 2006 e Kiev (Ucrânia) abril de 2008 (Lowe, 2008). rajando sua participação em governos municipais". ${ }^{8} \mathrm{O}$ financiamento foi dirigido às organizações que desenvolviam ações e políticas de oposição ao Governo Chávez, e algumas delas estiveram envolvidas no golpe de abril de $2002 .^{9}$

Na fundação do NED, definiu-se claramente uma estratégia na qual ele atuaria de forma ampla, enquanto as quatro organizações (CIPE, ACILS, IRI e NDI) teriam como foco espaços sociais mais específicos. Estabeleceu-se, assim, uma espécie de divisão de trabalho na atuação, para criar um consenso em favor de reformas políticas e econômicas ao redor do globo de acordo com interesses estratégicos do governo e das corporações norte-americanas. Assim, os dois institutos vinculados aos partidos Republicano e Democrata agiriam junto a organizações políticas, especialmente partidárias, enquanto caberia ao instituto vinculado à AFL-CIO atuar junto às organizações e aos movimentos da classe trabalhadora e ao CIPE, o universo empresarial.

A dinâmica dessa ação, no entanto, não inclui apenas as instituições tradicionais (partidos políticos e organizações dos trabalhadores e capitalistas, como os sindicatos e associações empresariais), mas envolve especialmente organizações da sociedade civil, como think tanks, ONGs e outras organizações. Examinar em que medida o NED e as quatro organizações logram articular sua atividade em um determinado país ou em uma conjuntura específica escapa às possibilidades analíticas deste artigo e da pesquisa em curso. A complexidade e diversidade dos países onde atuam bem como os próprios conflitos e divergências internas alertam sobre as dificuldades dessa articulação. Mas o risco maior talvez seja subestimar seu alcance e possibilidades. De qualquer forma, não é surpreendente constatar que, enquanto o CIPE apoia os programas de organização da agenda dos empresários peruanos, a ACILS estimula a organização dos trabalhadores mineiros terceirizados ou que, respectivamente, estejam apoiando, no Bra-

8 Informações coletadas no site do NED http:// www.ned.org/grants/06programas/highlights-lac06.htm. Acesso em: 12 maio de 2008.

9 Para uma análise detalhada da atuação do NED na Venezuela, ver especialmente Golinger $(2005,2006)$. 
Ary Cesar Minella

sil, o Instituto Brasileiro de Governança Corporativa e iniciativas das centrais e federações sindicais dos trabalhadores. ${ }^{10}$ Ao tratar dos casos específicos do Peru e da Argentina, identifico alguns dos projetos e parcerias desenvolvidos diretamente pelo NED. O CIPE passa a ser o foco central da análise na sequência deste artigo.

\section{CENTER FOR INTERNATIONAL PRIVATE ENTERPRISE (CIPE)}

Dentro da estratégia de atuação do NED de promoção da democracia e do livre mercado, cabe ao CIPE dirigir sua atuação para o universo empresarial, especialmente suas associações de classe e organizações da sociedade civil sob sua influência, buscando seu envolvimento na formulação e implementação de políticas públicas orientadas pelo interesse do mercado. Como foi mencionado, embora receba fundos governamentais, o CIPE é uma entidade privada, vinculada à Câmara Americana de Comércio.

Inicialmente, é importante resgatar algumas informações sobre essa organização empresarial. Segundo sua própria referência, a Câmara Americana de Comércio "é a maior federação empresarial do mundo e representa mais de três milhões de empresas de todos os portes, setores e regiões" e "inclui centenas de associações, câmaras de milhares de locais e mais de 100 Câmaras de Comércio Americanas em 91 países". ${ }^{11}$

Ao analisar a virada neoliberal nos Estados Unidos nos anos 1970, Harvey (2008) começa com o histórico memorando de Lewis Powell à Câmara de Comércio dos Estados Unidos em agosto de 1971, quando estava prestes a assumir um posto na Suprema Corte, indicado por Richard Nixon. Nesse documento, Powell faz uma defesa do sistema norte-americano de livre mercado, pois era necessário mobilizar esforços contra aqueles que

${ }^{10}$ Para uma análise da atuação do Solidarity Center junto às entidades sindicais dos trabalhadores no Brasil, ver Amorim (2007).

${ }^{11}$ U.S. Chamber of Commerce, www.uschamber.com Acesso em: 13 june 2008 . queriam destruí-lo. Para isso, a ação individual não seria suficiente. Segundo ele,

... a força reside na organização, no planejamento e na implementação meticulosos de longo prazo, na coerência da ação durante um período indefinido de anos, na escala de financiamento que só se obtém por meio do esforço conjunto e no poder político que só se obtém por meio da ação unida e de organizações de alcance nacional (Powell, 1971, apud Harvey, 2008, p. 52).

Powell propôs à Câmara de Comércio desenvolver uma ação direta junto às universidades, escolas, meios de comunicação, mercado editorial e cortes da justiça para reverter o quadro e mudar o pensamento das pessoas sobre "as corporações, o direito, a cultura e o indivíduo" (apud Harvey, 2008, p. 53)..$^{12}$ Segundo Harvey, “... é difícil dizer que influência direta teve essa injunção à entrada na luta de classe". Todavia - diz ele -, "sabemos que a Câmara de Comércio depois disso ampliou sua base de 60 mil empresas, em 1972, para mais de um quarto de milhão, dez anos mais tarde", e, associada à National Association of Manufacturers, reuniu muito recurso para fazer lobby e promover pesquisa (2008, p. 53).

O Quadro 1 mostra que, entre as 22 dessas Câmaras existentes na América Latina, pelo menos quinze foram criadas até 1981, das quais nove até a década de cinquenta. Mas no México, Argentina, Brasil e Chile, sua origem remonta ao período entre 1916 e 1919. Foram constituídas para defender os interesses das empresas norte-americanas em cada país, mas agregam empresas de diversas origens. Estão filiadas à Associação de Câmaras Americanas de Comércio na América Latina (Association of American Chambers of Commerce in Latin América - AACCLA), com sede em Washington, que, por sua vez, está filiada à Câmara Americana de Comércio (U.S. Chamber of Commerce).

${ }^{12} \mathrm{Na}$ época, Lewis era advogado de empresas e participava do conselho administrativo de 11 corporações. Esse documento ficou conhecido também como "Powell Manifesto" e está disponível em http:/www.reclaimdemocracy.org/ corporate_accountability/powell_memo_lewis.html. Para breves comentários sobre ele, ver, nesse mesmo endereço, o texto The Powell Memo, Introduction, de 3 de abril de 2004. 
Quadro 1 - Câmaras Americanas de Comércio na América Latina - Integrantes da Associação de Câmaras Americanas de Comércio na América Latina

(Association of American Chambers of Commerce in Latin America - AACCLA)

Argentina

Brasil - São Paulo (1919)*

Bolívia (1975)

Chile (1918)

Colombia - Bogotá (1955)

Costa Rica (1973)

Equador - Guayaquil (1980)

Equador - Quito

El Salvador

Guatemala

Haiti

Honduras

Jamaica (1986)

México (1917)

Nicarágua

Panamá (1979)

Paraguai (1981)

Peru (1968)

República Dominicana (1923)

Trinidad e Tobago (1992)

Uruguai (1934)

Venezuela (1953)

Fonte: Elaboração própria a partir das páginas das Câmaras na internet. (*) No Brasil, também está constituída a Câmara do Rio de Janeiro, fundada em 1916.

Assim, quando o CIPE foi criado, as corporações norte-americanas já haviam implantado, desde longa data, uma estrutura de representação de seus interesses na América Latina. OCIPE reconhece que sua filiação à Câmara de Comércio dos Estados Unidos facilitou a entrada na região. ${ }^{13}$

Apesar de ser vinculado à Câmara de Comércio, os fundos do CIPE provêm basicamente do governo dos Estados Unidos, que repassa uma parte diretamente através da USAID, e outra através do NED. Os recursos de outras fontes têm uma pequena participação (1\% em 2002; 6\% em 2004; $3 \%$ em 2005). Entre elas estão o próprio Departamento de Estado ${ }^{14}$ e organismos internacionais

${ }^{13}$ O Center for Leadership Development (CLD), da US Chamber of Commerce em cooperacão com o CIPE, criou o Latin American Institute for Organizations Management, que atua na formação do corpo gerencial das associações empresariais na região (Geurts et al, 2001, p. 64).

${ }^{14}$ Mantém (de longa data) uma parceria com o Departamento de Estado na publicação do jornal do CIPE, Economic Reform Today (Bohn, 2001, p. 17). como a ONU, o Banco Mundial e sua International Finance Corporation (IFC), além de ONGs como a Global Corporate Governance Forum e grandes empresas americanas (CIPE, Annual Report, 2003, p. 4). Algumas delas, como o Banco Mundial, também apoiam as organizações com as quais o CIPE tem parceria.

Desde sua fundação, o CIPE articulou sua ação financiando mais de 1000 organizações e iniciativas locais em mais de 100 países e conduziu programas de treinamento na administração de associações empresariais na África, Ásia, Europa, Eurásia, Oriente Médio e América Latina. Sua atuação principal realiza-se através das "parcerias" com organizações locais, especialmente com associações empresariais, think tanks, ONGs, universidades e outras organizações da sociedade civil. No desenvolvimento dos programas conjuntos, essas organizações locais entram com recursos obtidos de outras fontes.

Nos seus primeiros anos, a maior parte dos recursos do CIPE foi dirigida para a América Latina e o Caribe, no contexto das dramáticas mudanças que ocorreram nos anos 80. No final dessa década, segundo a avaliação do CIPE, “... quase todos os países da região haviam abandonado a política de substituição de importações em favor de um sistema econômico orientado pelo mercado" e "... quase todos os países haviam avançado na adoção de formas democráticas de governo" (Bohn, 2001, p. 14).

Segundo esse autor, nos primeiros anos, o CIPE concentrou seus programas naqueles países que haviam demonstrado um empenho favorável ao desenvolvimento das empresas privadas e da democracia. Mas posteriormente ficou claro que a abordagem do CIPE poderia ser aplicada em países onde o empenho governamental para o capitalismo e a democracia era fraco, desde que se encontrassem "dedicadas e corajosas" organizações parceiras. Foi assim, por exemplo, que o CIPE apoiou programas na Rússia e na Nigéria. Conforme a ideologia desse empreendimento, estimular o "... surgimento de associações empresariais e think tanks é parte vital da promoção da cultura democrática e impulso para reforma econômica" 
(Bohn, 2001, p. 15). Assim, no final dos anos 80 o CIPE ampliou suas operações, incluindo programas na África e na Ásia. Após a Queda do Muro de Berlim (1989) e as primeiras eleições "parcialmente livres" na Polônia e na Hungria, o Center passou a atuar na Europa Central e do Leste e, a partir de 1991, na Rússia e na Ucrânia. Em meados dos anos 90, havia estabelecido programas na China e no Vietnam (2001, p. 14-15).

Ao mesmo tempo, desde o começo dos anos 90, o CIPE ampliou suas parcerias com empresas, instituições multilaterais e organizações não-governamentais (ONGs). São exemplos disso as atividades realizadas com o World Bank Institute (programas de treinamento sobre thinktanks), com a Organização de Cooperação e Desenvolvimento Econômico (conferência sobre o combate à corrupção em países em desenvolvimento), e o trabalho com organizações privadas e públicas durante a Conferência do CIPE sobre a Mulher (Women: the emerging economic force), realizada em 2000 (Bohn, 2001, p. 17; CIPE, Anual Repport, 1998).

Uma avaliação sobre os primeiros quinze anos (1984-1999) de atuação do CIPE considerou o impacto de 365 projetos realizados com 200 "organizações parceiras" em 63 países e concluiu que $5 \%$ dos projetos tiveram um resultado excepcional, $25 \%$ um alto impacto, $53 \%$ um efeito médio e $17 \%$ deles situaram-se em nível baixo. (Geurts et al., 2001, p.1).

Na avaliação do CIPE, três programas se tornaram fundamentais: a) programas de treinamento realizados ao redor do mundo para dirigentes de associações empresariais, líderes de think tank e jornalistas econômicos; b) programas de apoio legislativo e econômico, especialmente para dar suporte à legislação e às reformas favoráveis ao livre mercado; c) rede de reforma econômica, estabelecida depois de ter realizado uma série de conferências ao redor do mundo e cujo objetivo é "estabelecer uma conexão entre as organizações parceiras do CIPE buscando compartilhar experiências e recursos, bem como definir agendas de reforma para o futuro" (Bohn, 2001, p. 16).

Segundo Geurts et al. (2001), as estratégias do CIPE estão focadas em reformas institucionais, e o "coração de todos os projetos do CIPE" é a "advocacy", que significa a promoção efetiva de uma legislação que leve a mercados abertos e encoraje a participação do setor privado na definição das políticas públicas. O objetivo é desenvolver políticas que fortaleçam os mecanismos de mercado e o avanço dos interesses empresariais. A articulação com as organizações locais é central na abordagem do CIPE, e elas devem ser ativas na elaboração e implementação dos projetos ("empoderamento das organizações locais", na linguagem do CIPE). Outro aspecto fundamental da ação do CIPE se realiza através do Business Association Management Training, que permite à organização identificar potenciais organizações parceiras e lideres, muitos dos quais, segundo o CIPE, acabam ocupando postos centrais no setor público e no privado. O CIPE desenvolve um programa de comunicação que joga um papel central em sua estratégia de construir demanda por reformas democráticas orientadas para o mercado. Uma variedade de canais é utilizada para divulgar informações, incluindo-se a internet e publicações. ${ }^{15}$ Na avaliação de John A. Bohn (2001, p. 9), na ocasião presidente do CIPE, o fato de trabalhar com organizações "parceiras" ao redor do mundo proporciona ao CIPE ricos inputs sobre as transformações em curso e permite identificar tendências centrais que ultrapassam as fronteiras nacionais e regionais e jogam importante papel na globalização. Se isso contribui para avaliar os mecanismos de funcionamento do mercado e a relação entre capitalismo e democracia - conforme acredita Bohn -, permite também redefinir ou incorporar novos programas de ação.

Os principais programas de ação incluem:a) o combate à corrupção; b) a promoção da governança corporativa; c) reformas institucionais para levar o setor informal para a economia formal; d) reforço do papel da mulher e da juventude (programas, cursos, organizações, educação); e) promoção da governança democrática;f) redução das discrepân-

15 A fonte menciona os sitios "Freedom for Economic Forum", The Economic Feature Service e a publicação Economic Reform Today (p. 7). 
cias de renda através da iniciativa empresarial; ${ }^{16} \mathrm{~g}$ ) desenvolvimento das associações empresariais; $h$ ) reforma na legislação e regulações que dificultam as atividades empresariais; i) acesso à informação, para alcançar maior transparência no governo, na divulgação e no entendimento dos princípios democráticos orientados para o mercado. ${ }^{17}$

Uma análise dos recursos efetivamente utilizados para esses programas constata uma prioridade para as associações empresariais e as reformas legais e do marco regulatório. Por exemplo, em 2006, a primeira área recebeu 38\% dos recursos, e a segunda, $18 \%{ }^{18}$ As associações empresariais são consideradas fundamentais para o setor participar na sociedade civil e atores-chave para a definição das políticas públicas. Portanto, o CIPE estabelece um vínculo estreito com essas organizações, estimulando e apoiando a participação dos empresários no processo político (CIPE, Annual Report 2004, cap. 1, p. 7-8). O Centro elaborou um manual de orientação para mobilizar a "comunidade empresarial" no sentido de influenciar na reforma de políticas públicas, estabelecendo as prioridades empresariais no campo legislativo e da regulação. ${ }^{19}$ Segundo avaliação publicada em 2002, esse manual alcançou grande sucesso no desenvolvimento de uma agenda empresarial nacional em países como o Haiti, Argentina, Ucrânia e em agendas regionais na Rússia. Além disso, estava em aplicação em países do Oriente Médio (CIPE. Annual Report 2002, p.41). Em 2003, o CIPE abriu escritórios no Afeganistão e no Iraque, com o objetivo de "desenvolver a capacidade de a comunidade empresarial contribuir para a

${ }^{16}$ O CIPE vem encorajando o desenvolvimento de iniciativas empresariais que gerem emprego e renda, especialmente através das pequenas e das microempresas. Mas as pequenas e médias empresas jogam também um papel político e devem ser mobilizadas para dirigir as reformas, e as associações empresariais seriam um instrumento efetivo para isso (BOHN, 2001).

${ }_{17}$ Cf. CIPE, http://www.cipe.org/about/AboutCIPE.pdf Acesso: 25/04/2008; e Bohn (2001).

${ }^{18} \mathrm{CIPE}$, http://www.cipe.org/about/AboutCIPE.pdf. Acesso: $25 / 04 / 2008$

${ }^{19}$ CIPE. Guía para la Agenda Nacional Empresarial. La Voz de las Empresas.- Disponível em: http:// www.cipe.org/regional/lac/pdf/spanishnba.pdf. Acesso: 05/09/2008. Essa orientação aos empresários se apresenta de forma mais aprofundada em publicação do CIPE organizada por Milner (1999) emergência de uma sociedade democrática estável” (CIPE, Annual Report, 2003, p. 133).

Na avaliação do CIPE, apesar da emergência de um consenso sobre a importância da democracia e da economia de mercado, muitos países não conseguem estabelecer arranjos institucionais favoráveis ao seu desenvolvimento. Assim, mesmo as melhores políticas teriam problemas de implementação em razão da "ausência de instituições e normas apropriadas”. O foco de atuação do CIPE é

... promover as reformas legais e institucionais necessárias para sustentar democraticamente uma economia aberta orientada pelo mercado: respeito ao papel das leis, transparência, sólida base para os direitos de propriedade, respeito aos contratos, acesso à justiça e uma imprensa livre (CIPE, Annual Report 2004, cap.1, p. 8-9).

Ao reconhecer os limites ou fracassos das políticas neoliberais, o CIPE se soma à interpretação segundo a qual as razões disso se devem ao fato de essas políticas não terem sido acompanhadas de reformas institucionais:

O fracasso das reformas do Consenso de Washington na América Latina forçou os formuladores de políticas a colocar mais atenção nas reformas institucionais, uma posição que o CIPE defende de longa data para a regiã̃o (CIPE. Annual Report 2002, p. 31).

Segundo o CIPE, essa é uma oportunidade para que os programas desenvolvidos pela organização tenham um impacto significativo na região.

\section{Atuação do CIPE na América Latina}

No período de 1984 a 1999, o CIPE financiou 109 projetos na América Latina e no Caribe, envolvendo 50 organizações em 19 países. Os recursos envolvidos nessa atividade atingiram US\$ 9.375.047 (Geurts et al, 2001, p. 60). O impacto desses programas foi considerado excepcional ou alto em $41 \%$ dos casos e médio em $50 \%$ deles, destacando, assim, a região como a dos melhores resultados que o CIPE teria alcançado no período. O apoio aos projetos foi maior entre 1984 a 1994, declinando nos cinco anos posteriores em favor 
das operações realizadas no Centro e Leste Europeu e na Eurásia. Na avaliação do CIPE, grande parte dos projetos apoiados foi importante para as reformas institucionais ocorridas nos países latino-americanos e outros contribuíram com elementos-chave para a governança democrática (democratic governance). No Quadro 4 (anexo), apresento uma lista das organizações na América Latina que, em diferentes momentos e com intensidades diversas, foram financiadas para desenvolver programas dentro dos interesses estratégicos no CIPE para o continente.

Segundo avaliações internas do CIPE, um dos elementos que explicaria o "sucesso" de sua atuação no continente é a capacidade de as organizações parceiras adaptarem os programas às condições locais de cada país. O Programa de Apoio Legislativo é mencionado como um exemplo nesse campo. Uma das formas principais de atuação do CIPE, o Programa foi inicialmente criado pelo Centro de Orientación Económica na República Dominicana (COE). Segundo Bohn (2001, p. 16), o programa baseava-se na análise "não-partidária" da legislação de modo acessível e apoiada por estudos em profundidade realizados por uma equipe de economistas e tecnocratas. Basicamente esses relatórios analisam as leis em debate no poder legislativo, resumem os efeitos da legislação sobre o setor público e privado, o orçamento nacional, o sistema legal e apresentam recomendações específicas para representação, revogação, rejeição ou emendas. Os relatórios são distribuídos entre os legisladores, a mídia e o público (CIPE. Annual Report 2003).

"Através de uma série de análises econômicas e relatórios, a comunidade empresarial foi hábil em inserir sua voz no processo de debate político." Segundo o CIPE, em pelo menos 12 países (até 1999), essa atividade foi realizada com sucesso, e os relatórios produzidos constituíram uma fonte de informação que permitiu aos legisladores participar e tomar decisões em questões econômicas fundamentais (Geurts et al, 2001, p. 65). ${ }^{20} \mathrm{O}$

${ }^{20}$ A avaliação dessa atividade indicou, segundo o CIPE, que $65 \%$ dos projetos de apoio legislativo tiveram um excepcional ou alto impacto na América Latina (Geurts et al, 2001, p.63). programa foi aplicado também na África, Ásia e Europa Central.

A Tabela 1 identifica, em fins dos anos $80 \mathrm{e}$ início dos 90, alguns dos parceiros e os principais programas apoiados pelo CIPE com o objetivo de influenciar o processo legislativo e implementar reformas em 11 países da América Latina, além de um programa regional (América Central). Os casos mencionados envolveram recursos em torno de US\$ US\$ 4.400.000,00, dos quais US\$ 2.866.690,00 $(65,2 \%)$ fornecidos pelo CIPE. ${ }^{21}$

A atuação com o IERAL (sigla adotada pelo Instituto a partir de 1996) na Argentina é o maior destaque, tanto pelo volume de recursos envolvidos (quase um milhão de dólares) como pela extensão do período (cinco anos). O CIPE inclui o IERAL como um dos três casos de maior sucesso de sua atuação na América Latina (os outros dois são o Instituto Libertad y Democracia, no Peru, e o COE, na República Dominicana). Chama a atenção o interesse do CIPE pelo Paraguai nesse período, pois o volume de recursos repassados para a Fundación Paraguaya para la Cooperación y el Desarrollo (FUPACODE) somente é superado pelos recursos canalizados para o IERAL e o Instituto Liberal do Rio de Janeiro (ILRJ). ${ }^{22}$

Na estratégia de divulgação das ideias e propostas de reforma na América Latina, o CIPE se vale também de Perspectiva, uma publicação trimestral distribuída em Argentina, Bolívia, Colômbia, Equador, Panamá, Uruguai, Venezuela, Peru e Chile. Três organizações apoiadas pelo CIPE são responsáveis pela produção da revista: o Instituto de Ciencia Política (ICP) na Colômbia, o Centro para a Diseminación de Informaciones Económicas (CEDICE) na Venezuela e o Instituto de Política Económica do Equador (CIPE. Annual Report, 2002). Em 2002, o

... foco dos programas do CIPE para a América Latina era a construção das instituições ausentes

${ }^{21}$ Em alguns casos, não consta, nas fontes, o aporte financeiro local para o programa.

${ }^{22}$ Além dos recursos canalizados através do CIPE, o NED atuou de forma intensa no Paraguai, segundo avaliação de Payne (1990), diretor de estudos hemisféricos da Freedom House de Nova York. 
Tabela 1 - CIPE. Programas de Apoio Legislativo na América Latina (1988-1993). Valores em US\$

\begin{tabular}{|c|c|c|c|c|c|}
\hline País/Região & Organização Local & Período & $\begin{array}{l}\text { Fundos do } \\
\text { CIPE }\end{array}$ & $\begin{array}{l}\text { Outras } \\
\text { fontes }\end{array}$ & Total \\
\hline Argentina & $\begin{array}{l}\text { Instituto de Estudios Económicos sobre } \\
\text { la Realidad Argentina y Latinoamericana } \\
\text { (IEERAL) * }\end{array}$ & $03 / 88$ a $03 / 93$ & 416.100 & 578.200 & 994.300 \\
\hline Bolívia & $\begin{array}{l}\text { Confederación de Empresários Privados } \\
\text { de Bolívia (CEPB) }\end{array}$ & $05 / 92$ a $04 / 93$ & 102.470 & - & 102.470 \\
\hline Brasil & Instituto Liberal do Rio de Janeiro (ILRJ) & $\begin{array}{c}\text { Meados de } 92 \text { a } \\
02 / 93\end{array}$ & 325.900 & - & 325.900 \\
\hline América Central** & $\begin{array}{l}\text { Federación de Entidades Privadas de } \\
\text { Centroamérica y Panamá }\end{array}$ & $\begin{array}{c}\text { Meados de } 91 \text { a } \\
02 / 94\end{array}$ & 210.000 & 95.000 & 305.000 \\
\hline Chile & $\begin{array}{l}\text { Instituto Latinoamericano de Doctrina y } \\
\text { Estudios Sociales (ILADES) }\end{array}$ & $02 / 90$ a $05 / 92$ & 229.200 & - & 229.200 \\
\hline Rep. Dominicana & Centro de Orientación Económica (COE) & 08/86 a $12 / 90$ & 268.000 & 143.000 & 411.000 \\
\hline Equador & $\begin{array}{l}\text { Asociación Nacional de Empresários } \\
\text { (ANDE) }\end{array}$ & $\begin{array}{l}\text { Meados de } 90 \\
\text { até } 93\end{array}$ & 193.260 & 107.850 & 301.110 \\
\hline El Salvador & $\begin{array}{l}\text { Asociación Nacional de la Empresa } \\
\text { Privada (ANEP) }\end{array}$ & $04 / 90$ a $10 / 93$ & 240.000 & 112.800 & 352.800 \\
\hline Nicarágua & $\begin{array}{l}\text { Consejo Superior de la Empresa Privada } \\
\text { (COSEP) }\end{array}$ & $\begin{array}{l}\text { Início de } 90 \text { a } \\
\text { fins de } 93\end{array}$ & 282.000 & 46.000 & 328.000 \\
\hline Paraguai & $\begin{array}{l}\text { Fundación Paraguaya para la } \\
\text { Cooperación y el Desarrollo } \\
\text { (FUPACODE) }\end{array}$ & $02 / 90$ a $03 / 93$ & 286.260 & 357.000 & 643.260 \\
\hline Peru & Instituto APOYO & 07/90 а 12/92 & 150.000 & 90.000 & 240.000 \\
\hline Uruguai & $\begin{array}{l}\text { Centro de Estúdios sobre la Realidade } \\
\text { Econômica e Social (CERES) }\end{array}$ & $\begin{array}{c}\text { 04/89 a meados } \\
\text { de } 93 \\
\end{array}$ & 163.500 & - & 163.500 \\
\hline \multicolumn{3}{|l|}{ Total } & $2.866 .690,00$ & & $4.396 .540,00$ \\
\hline
\end{tabular}

Fonte: Elaboração própria a partir de Mashek, 1993, p. 59-106; CIPE, Annual Report, 2003, cap. 3, p. 9.

(*) A partir de 1996, passou a denominar-se Instituto de Estúdios sobre la Realidad Argentina e Latinoamericana (IERAL).

${ }^{* *}$ Programa de Reforma Econômica Regional para a Integração da América Central.

em uma economia de mercado e dirigir-se ao déficit de governança democrática. Além disso, buscava apoiar os líderes empresariais e os pensadores pró-mercado na implementação das reformas institucionais e o papel da imprensa na investigação da corrupção nos setores público e privado (CIPE, Annual Report 2002, p. 31).

No relatório anual de 2004, o CIPE avaliou que se agudizara a "crise da democracia" na América Latina em países como Venezuela, Equador, Peru e Bolívia. Em 2007, desenvolvia 23 programas em 13 países da América Latina (Quadro 2).

Três programas eram de alcance regional: um para o desenvolvimento de governança corporativa na Colômbia, no Equador e na Venezuela (com a Confederación Colombiana de Cámaras de Comercio - CONFECAMARAS); outro programa para formação de liderança para "promover a democracia" e o terceiro voltado para a publicação da Perspectiva e a defesa das reformas (Instituto de Ciência Política).

A seguir, examino com mais detalhes a presença do CIPE no Peru e na Argentina e identifico também intervenções diretas do NED ou através dos institutos dos partidos Republicano (IRI) e Democrata (NDI).

\section{Os parceiros no Peru: o Instituto Libertad y Democracia (ILD) e o Instituto Apoyo.}

Segundo a avaliação do CIPE, o ILD é amplamente reconhecido por sua atuação em estabelecer um consenso em torno da economia de mercado no Peru durante os anos 80 e firma os pilares para os programas de reforma econômica durante os anos 90 (Geurts, et al, 2001, p.61). Fundador do ILD, a figura de destaque é Hernando De Soto, considerado pela publicação Time como um dos cinco maiores lideres inovadores na América Latina no século XX e um dos líderes do Novo Milênio, enquanto o The Economist considerou o ILD como um dos dois mais importantes think tanks no mundo (CIPE. Annual Report 2003, cap.6, p.6).

Entre 1981 e 1984, o ILD, então com um pequeno grupo de pesquisadores, analisou a situ- 
Quadro 2 - CIPE - Center for International Private Enterprise Programas e parcerias na América Latina - 2007

\begin{tabular}{|c|c|c|}
\hline País/Região & Programa & Parceiro \\
\hline Argentina & $\begin{array}{l}\text { Governança Corporativa (GC) em instituições financeiras; } \\
\text { adoção de padrões de GC }\end{array}$ & Fundación Centro de Estabilidad Financiera (CEF) \\
\hline Argentina & Congresso: assuntos tributários & $\begin{array}{l}\text { Centro de Implementación de Políticas Públicas para la } \\
\text { Equidad y el Crecimiento( CIPPEC) }\end{array}$ \\
\hline Bolívia & Fórum Econômico sobre Reformas Constitucionais & $\begin{array}{l}\text { Centro de Estudios de la Realidad Económica e Social } \\
\text { (CERES) }\end{array}$ \\
\hline Bolívia & Fortalecimento do desenvolvimento do país & Fundación Milenio \\
\hline Brasil & GC em empresas familiares no Brasil & Instituto Brasileiro de Governança Corporativa (IBGC) \\
\hline Chile & Desenvolvimento de GC & $\begin{array}{l}\text { Centro para el Gobierno de la Empresa - Facultad de } \\
\text { Ciencias Económicas y Administrativas,Universidad } \\
\text { Católica de Chile (FEAUC) }\end{array}$ \\
\hline Colômbia & Treinamento de diretores de organizações empresariais & $\begin{array}{l}\begin{array}{l}\text { Confederación Colombiana de Cámaras de Comercio } \\
\text { (CONFECAMARAS) }\end{array} \\
\end{array}$ \\
\hline Colômbia & GC em empresas públicas e privadas & CONFECAMARAS \\
\hline Colômbia & $\begin{array}{l}\text { Consultoria sobre reforma econômica a atores-chave, } \\
\text { políticos e judiciais. }\end{array}$ & $\begin{array}{l}\begin{array}{l}\text { Fundación para la Educación Superior y el Desarrollo } \\
\text { (FEDESARROLLO) }\end{array} \\
\end{array}$ \\
\hline Cuba & Promoção de reformas em Cuba & \\
\hline Equador & Desenvolvendo consenso: competitividade e liderança & $\begin{array}{l}\text { Instituto Ecuatoriano de Economía Política (IEEP); e } \\
\text { Asociación Nacional de Empresarios (ANDE ) }\end{array}$ \\
\hline Equador & $\begin{array}{l}\text { Desenvolvimento de apoio público para economia de } \\
\text { mercado }\end{array}$ & IEEP \\
\hline Equador & Desenvolvimento de liderança para combater a corrupção & Fundación Alternativa para el Desarrollo (FA) \\
\hline Guatemala & $\begin{array}{l}\begin{array}{l}\text { Desenvolvimento de consenso para reduzir o setor } \\
\text { informal }\end{array} \\
\end{array}$ & Centro de Investigaciones Económicas Nacionales (CIEN) \\
\hline Haiti & $\begin{array}{l}\text { Fortalecimento da Câmara de Comercio e Indústria do } \\
\text { Haiti e das associações do setor privado }\end{array}$ & Cámara de Comercio y Industria de Haití (CCIH) \\
\hline México & Fortalecimento da GC & Centro de Excelencia en Gobierno Corporativo (CECG) \\
\hline Nicarágua & $\begin{array}{l}\text { Promoção da democracia através da Agenda Nacional } \\
\text { Empresarial }\end{array}$ & Consejo Superior de la Empresa Privada (COSEP) \\
\hline Peru & Treinamento em GC & Universidad Peruana de Ciencias Aplicadas (UPC) \\
\hline Peru & Defesa de reformas econômicas & $\begin{array}{l}\begin{array}{l}\text { Confederación de Instituciones y Empresas Privadas } \\
\text { (CONFIEP) }\end{array} \\
\end{array}$ \\
\hline Venezuela & Programa Educacional para líderes comunitários & Liderazgo y Vision \\
\hline Regional & $\begin{array}{l}\text { Revista "Perspectiva" (Promoção de reformas na América } \\
\text { Latina) }\end{array}$ & Instituto de Ciencia Política (IPC -Colombia) \\
\hline Regional & $\begin{array}{l}\text { Desenvolvimento de liderança para promover a } \\
\text { democracia na América Latina }\end{array}$ & \\
\hline Regional & Promoção de GC na Colômbia, Equador e Venezuela) & CONFECAMARAS (Colombia) \\
\hline
\end{tabular}

Fonte: CIPE. Annual Report 2007, p. 37.

Disponível em: http://www.cipe.org/publications/report/2007/CIPE_2007_AR_LAC.pdf . Acesso: 4/10/2008

CADERno CRH, Salvador, v. 22, n. 55, p. 13-40, Jan./Abr. 2009 
ação do mercado informal no Peru e passou a defender um processo de mudança que teria permitido reduzir drasticamente o procedimento de registro legal de um negócio, o que teria ajudado milhares de empresas a passarem do setor informal para o formal da economia (Geurts, et al, 2001, p. 61; Islam, 2007). De Soto avaliou que uma das formas de superar a economia informal e o atraso do capitalismo em geral, no Peru, era legalizar os títulos de propriedade dos lotes urbanos e habitações da população pobre, criando, assim, a possibilidade de utilizá-los para garantir o acesso a serviços (água, eletricidade) e como garantia na obtenção de empréstimo para pequenos negócios (Islam, 2007, p. 55). Segundo relatório de 2003, 380 mil empresas haviam ingressado no mercado formal e gerado 560 mil empregos formais adicionais, incrementando a arrecadação fiscal em 300 milhões de dólares (CIPE. Annual Report 2003, cap. 6, p. 6). ${ }^{23}$

Em 1984, o ILD recebeu os recursos do primeiro programa de apoio do CIPE. Isso teria contribuído para criar um sistema mais estável de governo e minar o apoio ao Sendero Luminoso, constituindo-se, assim, na avaliação do CIPE, em uma abordagem alternativa para "combater o terrorismo" (CIPE, Annual Report 2003, cap. 1, p. 2; cap. 6, p. 13). Segundo Islam (2007), a obra de Soto (The Other Path: The invisible revolution in the Third World), publicada em 1986, oferecia "aos pobres uma alternativa à revolução: o empreendedorismo" [entrepreneurship]. ${ }^{24}$ Essa perspectiva, que também identificava, na debilidade das instituições, a barreira primária para o crescimento empresarial e destacava a importância do desenvolvimento de instituições (como garantia de contratos, mercado financeiro e sistema judicial), recebeu uma boa acolhida no CIPE e passou a ser divulgada nas organizações multilaterais (Islam, 2007, p. 55-56).

Para sua atuação política no Peru nos anos

${ }^{23} \mathrm{O}$ tempo para o registro legal de um negócio passou de 289 dias para apenas 1 dia (Geurts, et al, 2001, p.61). O Congresso Peruano aprovou uma lei de simplificação administrativa em 1989.

${ }^{24}$ Segundo o CIPE, essa obra teria revolucionado a maneira de pensar dos acadêmicos, especialistas em desenvolvimento e governantes sobre o papel do direito de propriedade (CIPE, Annual Report 2003, cap.1, p.2).
90, o CIPE estabeleceu vínculos com outra organização do país: o Instituto APOYO. Organizado em 1989 para realizar pesquisa de política econômica, esse instituto está vinculado à APOYO, uma entidade privada de consultoria empresarial criada em 1977, durante o governo militar. No âmbito do CIPE, ela era considerada uma entidade "estável, consistente, confiável e profissional” (Mashek, 1993, p. 100). Segundo Mashek ela era responsável pelo mais confiável indexador de preços ao consumidor usado no país, havia atuado em consultoria política e econômica para grandes empresas privadas, realizava pesquisas internacionais de opinião pública. Além de estudos de mercado e pesquisas econômicas, publicava dois jornais econômicos e uma revista. ${ }^{25}$

O Instituto APOYO passou a realizar o serviço de assessoria legislativa, justamente no momento em que o governo de Fujimori iniciava seu programa de estabilização financeira e reforma econômica. Assim, entre julho de 1990 e fins de 1992, o CIPE financiou com US\$150.000,00 o programa de Apoio ao Congresso (Congressional Support) do Instituto, que, de sua parte, aportou para o programa US\$ 90.000,00. Na avaliação de Mashek (1993, p. 100), o serviço de relatórios legislativos mensais foi recebido com grande entusiasmo no Congresso, incluindo parlamentares da "esquerda moderada". O serviço "era novo no Peru, e ainda único" e também alimentava a imprensa diária, editoriais e colunistas além de painéis de discussão nos canais de televisão (1993).

O serviço sofreu descontinuidade quando o Congresso foi fechado em abril de 1992. Mas a formação da Assembleia Constituinte mobilizou o CIPE e o APOYO para revisar e apresentar propostas sobre os itens econômicos. Conforme as informações de Mashek (1993, p. 101), as propostas foram consolidadas em quatro relatórios distri-

\footnotetext{
${ }^{25}$ Segundo levantamento realizado pelo Foreign Policy Research Institute (FPRI) da Filadélfia, em um universo de 5080 think tanks e organizações da sociedade civil, 408 estão na América Latina, dos quais 21 no Peru. O Instituto Apoyo foi considerado como um dos cinco melhores think tanks do continente. Os demais são da Argentina (dois), do Brasil e do Chile (Disponível em: www.apoyo.com. Acesso em: 04/09/2008).
} 
buídos para o Congresso, para o Executivo, para a imprensa e a comunidade empresarial, além de outras instituições. Uma série de encontros foi planejada com os parlamentares encarregados da matéria econômica, e alguns deles teriam trabalhado em estreita relação com o Instituto APOYO. Também se estabeleceu contato e coordenação com o Ministério da Economia. Mashek (1993, p. 101) avaliou que a instituição APOYO desempenharia um papel fundamental no ordenamento e implementação das medidas de liberalização econômica e que seria equiparado unicamente àquele desempenhado por outra organização peruana de prestígio nacional e internacional, e também parceira do CIPE, o Instituto Libertad y Democracia (ILD). É importante ter presente que, nesse período (fins dos anos 80 e início dos 90), conforme foi mencionado, o CIPE financiou programas de apoio legislativo em 11 países da América Latina, além de um programa regional para a América Central (Quadro 2).

Os vínculos do CIPE no Peru, durante o período 2002 a 2007, estão identificados no Quadro 3. O Instituto APOYO está presente até 2005 e, nesse ano, em parceria com o CIPE, realizou uma série de discussões que serviram de base para a definição de uma Agenda Empresarial Nacional para o Peru e que representa todo um programa de governo que visava às eleições presidenciais de 2006. No período de 2005 a 2007, o CIPE apoiou iniciativas para o desenvolvimento da governança corporativa no país, em parceria com a Asociación de Empresas Promotoras del Mercado de Capitais (PROCAPITALES) $^{26}$ e a Universidad Peruana de Ciencias Aplicadas (UPC) (CIPE, Annual Report, 2005-2007). ${ }^{27}$

A partir de 2006, o CIPE passou a apoiar as atividades da Confederación de Instituciones y Empresas Privadas (CONFIEP), uma organização fundada em 1984 e que reúne a maioria dos setores empresariais do país, incluindo a Asociación de Bancos de Peru (ASBANC). Em pauta, a atualização da Agenda Nacional de Reformas Econômicas no Peru e a implementação das reformas de institucionais que, segundo essa Confederação, não teriam avançado o suficiente no país. Entre os pontos, há a revisão e difusão da agenda de reformas para o novo Congresso, a reforma educacional e o papel dos empresários nela. ${ }^{28}$

Para melhor compreensão do significado da

Quadro 3 - Parcerias do CIPE no Peru (2002-2007)

\begin{tabular}{|l|l|}
\hline \multicolumn{1}{|c|}{ Período } & \\
\hline 2002 & Instituto APOYO \\
\hline 2003 & - \\
\hline 2004 & $\begin{array}{l}\text { Instituto APOYO } \\
\text { El Comercio (Jornal). } \\
\text { PROCAPITALES (Asociación de Empresas Promotoras del Mercado de Capitales) }\end{array}$ \\
\hline 2005 & $\begin{array}{l}\text { Instituto APOYO } \\
\text { PROCAPITALES } \\
\text { Universidad Peruana de Ciencias Aplicadas (UPC) }\end{array}$ \\
\hline 2006 & $\begin{array}{l}\text { PROCAPITALES } \\
\text { CPC } \\
\text { CONFIEP (Confederación de Instituciones y Empresas Privadas) }\end{array}$ \\
\hline 2007 & $\begin{array}{l}\text { UPC } \\
\text { CONFIEP }\end{array}$ \\
\hline
\end{tabular}

Fonte: CIPE, Anual Repport, 2002, 2004, 2005, 2006, 2007.

${ }^{26}$ Fundada em 18 de julho de 2001, com sete associados, atualmente reúne 50 empresas. Seu objetivo é “... contribuir para o desenvolvimento do mercado de capitais no Peru através de um marco legal eficiente e implementação das melhores práticas de governança corporativa.” (Disponível em: www.invertir.or.pe. Acesso em: 04/09/2008).

\footnotetext{
${ }^{27} \mathrm{Em}$ 2005, foi realizada uma pesquisa sobre Governança Corpororativa com 4 mil empresas peruanas.

${ }^{28}$ Disponível em: www.confiep.org.pe. Acesso: 04/09/ 2008. A Confederação empresarial também desenvolve atividades com o IFC do Banco Mundial, em relação ao projeto municipal de simplificação de trâmites.
} 
Tabela 2 - NED - Organizações parceiras e recursos financeiros. Peru (2000-2007)

\begin{tabular}{l|r}
\hline \multicolumn{1}{c|}{ Organizações } & $\begin{array}{c}\text { Valores } \\
\text { (em US\$) }\end{array}$ \\
\hline TOTAL & $5.563 .741,00$ \\
\hline Partidos políticos (Através do IRI) & 1.974 .998 \\
\hline Partidos políticos (Através do NDI) & 513.844 \\
\hline Foro Democrático (Através do IRI) & 380.000 \\
\hline Instituto de Estudios Estratégicos y Políticos & 377.017 \\
\hline Instituto APOYO (em associação com CONFIEP em 2006). & 346.837 \\
\hline Consejo de la Prensa Peruana & 318.680 \\
\hline Instituto de Defensa Legal & 280.171 \\
\hline Comisión Andina de Juristas & 276.869 \\
\hline Consejo Nacional para la Ética Pública - Proética & 252.295 \\
\hline Consorcio de Investigación Económica y Social (CIES) & 121.796 \\
\hline Centro de Capacitación J.M. Arguedianos & 115.000 \\
\hline Instituto de Prensa y Sociedad & 100.000 \\
\hline Asociación de Jueces para la Justicia y Democracia del Perú & 90.000 \\
\hline Asociación Negra de Defensa y Promoción de los Derechos Humanos & 70.000 \\
\hline Governança Corporativa (Conferências) (Através do CIPE) & 59.232 \\
\hline Foro Nacional/Internacional & 56.200 \\
\hline Ciudadanos al Día & 54.670 \\
\hline Socios Peru - Centro de Colaboración Cívica & 39.900 \\
\hline Ciudad Nuestra & 39.713 \\
\hline Comisión Diocesana de Servicio Pastoral Social & 36.495 \\
\hline Comisión de Solidaridad, Desarrollo y Justicia & 34.994 \\
\hline Consultores en Planificación & 25.030 \\
\hline
\end{tabular}

Fonte: Elaboração própria, a partir dos Relatórios do NED (NED. Latin America and the Caribbean Program)

Disponível em: http:/www.ned.org/grants/

Obs.: Não inclui financiamento a projetos regionais. Detalhes se encontram na Tabela 6 (em anexo).
Mediterránea, à qual está vinculado. ${ }^{29}$ Em 1996, passou a denominar-se Instituto de Estudios de la Realidad Argentina y La tin o a m e ric a n a (IERAL).

O objetivo da Fundación é promover a pesquisa sobre questões econômicas, para criar um espaço para discussão e formulação de propostas de políticas econômicas a partir da perspectiva empresarial. "A metodologia de trabalho imposta pela Fundación Mediterránea, desde sua criação, é a interação permanente entre empresários e técnicos." (IERAL, 2005). O IERAL contou com uma equipe de economistas dedicados em tempo integral à pesqui- atuação do CIPE no Peru, é necessário ter presente o conjunto de organizações com as quais o NED atuou (e atua) nesse país e o volume de recursos utilizados. No período de 2002 a 2007, foram canalizados US\$ 5,5 milhões de dólares para uma gama diversificada de organizações (não estão incluídos os valores para projetos regionais do NED dos quais o Peru participa), conforme se apresenta na Tabela 2. Os detalhes sobre o financiamento recebido ano a ano se encontram na Tabela 6 (em anexo).

\section{Os parceiros do CIPE na Argentina: IERAL, CIPPEC e CEF}

O Instituto de Estudios Económicos de la Realidad Argentina e Latinoamericana (IEERAL) foi organizado em 1977 por empresários na cidade de Córdoba juntamente com a Fundación sa. Domingo Cavallo, presidente do Instituto, assumiu o Ministério da Economia em janeiro de 1991 e formou parte de sua equipe com pesquisadores do Instituto (Ramirez, 2006, p. 187-188). Segundo Geurts et al (2001, p. 61), muitos dos relatórios produzidos pelo IERAL serviram de base para as propostas de reforma da economia argentina adotadas por Cavallo. Conforme já mencionado, o Programa de Apoio ao Legislativo, desenvolvido entre março de 1988 e fevereiro de 1993 naquele país, canalizou quase um milhão de dólares, dos quais cerca de US\$ 450 mil saíram dos fundos do CIPE (ver Tabela 1).

29 Para uma análise detalhada sobre a Fundación Mediterránea e o IERAL, ver os trabalhos de RAMÍREZ (2000, 2006). Esse autor faz uma interessante análise comparativa entre o Instituto de Pesquisas Econômicas e Sociais - IPES, que teve papel central no golpe de Estado de 1964 no Brasil, e as organizações argentinas Fundación de Investigaciones Econômicas Latinoamericanas (FIEL) e a Fundación Mediterrânea. 
A partir de meados dos anos 90, o Instituto ampliou suas pesquisas para outras áreas, como educação, saúde, justiça e seguridade, e sua influência teria se estendido também para outras reformas, como a do trabalho, lei do consumidor, taxa de administração e reforma do serviço civil (Geurts et al, 2001, p. 61; CIPE. Annual Report, 2003, cap. 3, p. 5-6). O Banco Interamericano de Desenvolvimento (BID) e o Banco Mundial também financiam projetos desenvolvidos pelo IERAL. ${ }^{30}$

O apoio do CIPE ao IERAL aparentemente diminuiu a partir da crise econômica que assolou o país em 2001-2002 ${ }^{31}$ e que, segundo Braum et al (2004), levou também a um questionamento de um conjunto maior de think tanks como fonte de análise política e recrutamento de quadros para o Estado. ${ }^{32} \mathrm{~A}$ Tabela 3 sintetiza as parcerias do CIPE na Argentina e recursos envolvidos para o período 2002-2007.

A partir de 2002, o CIPE passou a apoiar o Centro de Implementación de Políticas Públicas para la Equidad y el Crecimiento (CIPPEC), organização que procura desenvolver um consenso sobre a necessidade de reforma política e econô- mica na Argentina. ${ }^{33}$ Em pouco tempo, além do CIPE, o Centro passou a contar com apoio de várias fundações e organizações da sociedade civil e recursos de organismos como o Banco Mundial e o Banco Interamericano de Desenvolvimento (BID). ${ }^{34}$ Mas é importante destacar que o apoio do NED ao CIPPEC foi muito mais amplo e, provavelmente, fundamental para consolidá-lo. Assim, além do CIPE, o NED canalizou recursos ao CIPPEC de forma direta e especialmente através do IRI. No período de 2002 a 2007, o CIPPEC recebeu dessas organizações mais de US\$ 900 mil (somente o IRI foi responsável por US\$ 525 mil), conforme Tabela 4.

O CIPPEC atua na formulação e na implementação de políticas públicas. Sua ação se volta para o Congresso, o governo e o público em geral, produzindo informações e análises sobre desenvolvimento social e econômico, e o fortalecimento das instituições, "através de programas de educação, saúde, política fiscal, justiça, transparência, instituições políticas, gestão pública local, incidência da sociedade civil e formação de líderes públicos para a democracia" (http://www.cippec.org/).

A estratégia do Centro é articular autorida-

Tabela 3 - CIPE - parcerias na Argentina (2002-2007)

\begin{tabular}{l|l|c}
\hline & \multicolumn{1}{|c}{ Organização } & \multicolumn{1}{|c}{ Valor US\$ } \\
\hline 2002 & CIPPEC (Centro de Implementación de Políticas Públicas para la Equidad y el Crecimiento) & $111.130,00$ \\
\hline 2003 & IERAL (Instituto de Estudios sobre la Realidad Argentina y Latinoamericana & - \\
\hline 2004 & CIPPEC & $100.912,00$ \\
\hline 2005 & CIPPEC & $89.276,00$ \\
\hline 2006 & $\begin{array}{l}\text { CIPPEC } \\
\text { Fundación Centro de Estabilidad Financiera (CEF ) }\end{array}$ & - \\
\hline 2007 & $\begin{array}{l}\text { CEF } \\
\text { CIPPEC }\end{array}$ & $143.801,00$ \\
\hline
\end{tabular}

Fonte: Elaboração própria, a partir de a) CIPE, Anual Repport, 2002, 2003, 2004, 2005, 2006, 2007; b) NED. Latin America and the Caribbean Program, 2002 a 2007 (para os valores). Disponível em: http://www.ned.org/grants/

${ }^{30}$ Fontes de financiamento do IERAL em 2003: 50\% de "organizações filantrópicas" argentinas, 25\% de organizações internacionais ("filantrópicas e de crédito"), 15\% com recursos governamentais (diferentes níveis) e o restante de contribuicõos empresariais e individuais (Fonte: Informação de Gabriel Sánchez, Diretor de Pesquisa e Vice-presidente do IERAL, em março de 2004. Disponível em: http://www. researchandpolicy.org/consultas. Acesso em: 25/09/2005.)

${ }^{31}$ As referências ao IERAL no relatório do CIPE de 2003 são pouco precisas. Informa apenas que o Instituto continua realizando a atividade de análise legislativa para influenciar o congresso e a opinião pública.

${ }^{32}$ Além de Domingo Cavallo, Humberto Petrei e Aldo Dadone, da Fundación Mediterránea, membros do Cen-

tro de Investigaciones Sociales sobre el Estado (CISEA) como Dante Caputo e Felipe Sola e do Centro de Estudios Macroeconómicos de Argentina (CEMA), como Roque Fernandez e Carlos Rodriguez, também ocuparam importantes postos no comando do Estado (Braum, et al, 2004).

33 Entre os onze "jovens profissionais" que fundaram o CIPPEC em 2000, oito tinham em comum sua formação (mestrado ou doutorado) na Harvard University (quatro em Políticas Públicas, três em Economia, um em Administração Pública e outro em Política Educacional). Os demais fundadores tiveram formação na London School of Economics, na Northwestern University e na University of Chicago (Disponível em: http://www.cippec.org/espanol/ cippec/fundadores.html. Acesso em: 29/09/2008).

${ }^{34}$ Além da capital, o CIPPEC atua em onze províncias argentinas e conta com um staff de oitenta e duas pessoas. 
Tabela 4 - Centro de Implementación de Políticas Públicas para la Equidad y el Crecimiento (CIPPEC) - Recursos recebidos do NED diretamente ou através do CIPE e do IRI 2002-2006

\begin{tabular}{|c|c|c|}
\hline Ano & Organização & Valores (US\$) \\
\hline 2002 & CIPE & $111.130,00$ \\
\hline 2003 & IRI & $300.000,00$ \\
\hline \multirow{2}{*}{2004} & IRI & $225.000,00$ \\
\hline & CIPE & $100.912,00$ \\
\hline \multirow{2}{*}{2005} & NED & $50.913,00$ \\
\hline & CIPE & $89.276,00$ \\
\hline 2006 & NED & $41.328,00$ \\
\hline \multicolumn{2}{|l|}{ TOTAL } & $918.559,00$ \\
\hline
\end{tabular}

Fonte: Elaboração própria, a partir dos Relatórios do NED (NED. Latin America and the Caribbean Program), disponíveis em http:/www.ned.org/grants/ Acesso em: 31/10/2008.

des governamentais nacionais e regionais, líderes empresariais, jornalistas, representantes das organizações civis e o público. Estabeleceu, assim, um amplo leque de alianças com outras organizações, universidades e centros de pesquisa no país e no exterior. O CIPPEC busca influenciar a definição de uma agenda de reformas e promover a participação e inclusão do setor privado na formulação de políticas públicas (CIPE, Annual Report 2002 e 2007).

No Congresso Argentino, o CIPPEC distribui análises e recomendações de política fiscal. Organizou seminários sobre o tema e lançou uma campanha para promover a reforma fiscal (CIPE, Annual Report, 2005). Em 2007, propôs a criação de uma Comissão Orçamentária no Congresso, que teria recebido um amplo apoio (CIPE, Annual Report, 2007). O Congresso argentino institucionalizou o Seminário Anual sobre Federalismo Fiscal, o que teria levado a ampliar o reconhecimento desse tema para o desenvolvimento sustentável. Segundo o relatório do CIPE de 2007, o Congresso aprovou a Lei sobre Financiamento da Educação, que incorporou recomendações do CIPPEC “... destinadas a garantir a transparência e a publicação de informações sobre educação, investimentos e atribuições, entre outras". Informa também que o CIPPEC estava trabalhando com o Ministério da Educação para avaliar o cumprimento dos objetivos da lei. ${ }^{35}$

${ }^{35}$ Além disso, o CIPPEC teria influenciado no melhoramento da lei que regulamenta imposto sobre o valor agregado na indústria do pão (defendeu a eliminação de disparidades, que criava uma taxa de 10,5 por cento iguais para toda cadeia de abastecimento).
Programas educacionais desenvolvidos na província de San Luis foram acompanhados pelo CIPPEC, que também esteve envolvido formulação das políticas para a área (Braum, et al, 2004, p. 211).

A atuação do Centro realiza-se também junto às organizações da sociedade civil e coordena, na América Latina, o Programa de Alianzas de la Sociedad Civil do Instituto para o Desenvolvimento Internacional (Overseas Development Institute-ODI), uma think tank britânica financiada por outras fundações de pesquisa, organizações internacionais, ONGs e empresas. O objetivo “... é fortalecer o trabalho em rede das organizações para uma melhor participação e influência nas políticas públicas”. ${ }^{36}$

Em 2006, dentro de sua estratégia de apoiar a governança corporativa na América Latina, o CIPE articulou sua atuação com a Fundación Centro de Estabilidad Financiera (CEF), a fim de desenvolver um padrão para medir a qualidade de práticas de governança corporativa nas instituições financeiras na Argentina. Também desenvolveu um código de ética e de responsabilidade social para servir como um guia para instituições financeiras, bem como para agências financeiras reguladoras (CIPE, Annual Report 2006).

Como foi mencionado também para o caso argentino, uma compreensão melhor do significado da atuação do CIPE se faz tendo presente o conjunto de organizações com as quais o NED atuou (e atua) nesse país e o volume de recursos utilizados. No período de 2002 a 2007, foram canalizados quase US\$ 2,5 milhões, para uma gama diversificada de organizações (não estão incluídos os valores para projetos regionais do NED), conforme Tabela 5. Os detalhes sobre os recursos utilizados ano a ano se encontram na Tabela 7 (em anexo). Os dados revelam o importante papel atribuído ao CIPPEC (recebeu mais de US\$ 900 mil).

${ }^{36}$ Cf. CIPPEC, Newsletter 26 - Octubre 2006. Disponível em: http://cippec.org/espanol/newsletter/n26/ Proyecto_1.htm. Acesso em: 29/09/2008; ODI, http://www.odi.org.uk/ about.html. Acesso: 29/9/2008. 
Tabela 5 - NED - Parcerias (diretas ou através do IRI e CIPE). Argentina (2002-2007)

\begin{tabular}{l|r}
\hline \multicolumn{1}{c|}{ Parceiro Local } & \multicolumn{1}{c}{ Total US\$ } \\
\hline TOTAL & $2.462 .768,00$ \\
\hline CIPPEC & $918.559,00$ \\
\hline Poder Ciudadano & $323.813,00$ \\
\hline Fundación. Nueva Generación Argentina & $278.371,00$ \\
\hline Asociación por los Derechos Civiles & $247.504,00$ \\
\hline Fund. Centro de Estabilidad Financiera (CEF) & $243.586,00$ \\
\hline Centro de Estudios Legales y Sociales & $183.460,00$ \\
\hline Asociación Civil por la Igualdad y la Justicia & $113.625,00$ \\
\hline Fundación Cambio Democrático & $38.505,00$ \\
\hline El Ágora & $30.000,00$ \\
\hline Ejercicio Ciudadano & $29.885,00$ \\
\hline Foro de Periodismo Argentino & $27.810,00$ \\
\hline $\begin{array}{l}\text { Fund. Familiares de Víctimas Indefensas } \\
\text { de Mendoza }\end{array}$ & $27.650,00$ \\
\hline
\end{tabular}

Fonte: Elaboração própria, a partir de NED. Latin America and the Caribbean Program. Disponível em: http:/www.ned.org/grants/ Obs.: Não inclui Projetos Regionais do NED. A Tabela 7 (em anexo) identifica os recursos utilizados em cada ano.

\section{Estratégias do CIPE para o período 2007-2012}

Em fevereiro de 2007, o CIPE divulgou um documento com a estratégia da organização para o período de 2007-2012. ${ }^{37}$ As considerações seguintes estão baseadas nesse documento.

Na avaliação do CIPE, a emergência do "populismo" e do "protecionismo" são dois grandes desafios a serem enfrentados nesse período. Esse "novo populismo", segundo o documento, procura desvincular a liberalização política das reformas de livre mercado e livre comércio e, ao mesmo tempo, busca reforçar laços políticos e econômicos regionais contrários à reforma global. Isso formaria o núcleo do que se denominaria "recuo da democracia” (democracy backlash). "O desafio para os próximos anos é sustentar o ímpeto das reformas democráticas e do livre mercado" (CIPE, 2007, p. 3).

Na América Latina, alguns países estariam vinculados ao "recuo democrático". Venezuela, Bolívia e Argentina são exemplos citados no documento de planejamento estratégico. O presiden-

${ }^{37}$ CIPE. Five year strategy 2007-2012. Center for International Private Enterprise, February 2007. Disponível em: http://www.cipe.org/about/strategy5year.pdf. Acesso em: 25/04/2008. te Hugo Chávez é considerado como responsável pelo desenvolvimento de um sistema político com um Poder Executivo sem controle, enquanto, na Argentina, a presidência estaria concentrando superpoderes em detrimento do Congresso, e, na Bolívia, o presidente "demonstrou desprezo pelo Estado de Direito e pelos direitos de propriedade, por nacionalizar hidrocarboneto e ter avançado na expropriação de terras". Deixando claro como esses casos estariam no centro da estratégia do CIPE para a América Latina, o documento afirma: “ $E$ essencial que se desenvolvam estratégias de combate a essas ameaças ao longo dos próximos cinco anos" (p. 34 - grifo meu). Os programas do CIPE nesses países, em 2007, se encontram no Quadro 2. Nesse mesmo ano, o NED apoiou um conjunto de organizações na Venezuela. ${ }^{38}$

O CIPE considera que, apesar dos resultados macroeconômicos positivos em muitos países da região, existe um questionamento sobre a "qualidade do desenvolvimento" e sondagens de opinião apontam claramente que a população, apesar de apoiar a democracia, também está frustrada por não ser beneficiada diretamente pelo sistema (p. 35-36). São necessários esforços para criar instituições que tratem a "frustração popular" e criem prosperidade para a maioria da população da região. $\mathrm{O}$ fortalecimento das instituições inclui uma reforma política, o reforço dos direitos de propriedade e estruturas jurídicas que garantam o cumprimento das leis. Reformas institucionais são fundamentais para garantir uma democracia verdadeira e sustentável, segundo o documento (p. 35).

Está clara a estratégia de manter as articulações com organizações localizadas na América Lati-

${ }^{38}$ Em 2007, o NED apoiou 18 programas no país com um volume de recursos de US\$ 938 mil, dos quais US\$ 300 mil se dirigiram a programas de "civic education" e US\$ 360 mil para o "fortalecimento" de ONGs e programas de direitos humanos; através do IRI, US\$ 100 mil foram canalizados para organizar dois encontros entre líderes políticos nacionais e locais e o desenvolvimento de campanhas públicas; o Instituto Prensa y Sociedad recebeu outros US\$ 102 mil (Cf. NED, Latin América and the Carribean 2007. Disponível em: http://www.ned.org/ grants/07programs/grants-lac07.html. Acesso em: 01/11/ 2008). Nã̃o incluem recursos dos programas regionais do NED que afetam a Venezuela, especialmente aqueles que se realizam através do Solidarity Center dirigidos às organizações dos trabalhadores. 
na, especialmente thinktanks, associações empresariais e organizações da sociedade civil. Cinco temas foram considerados como foco da atuação a ser desenvolvida. O primeiro deles é atuar na formação de propostas econômicas para os partidos políticos. O objetivo é combater as propostas "populistas" e desenvolver uma abordagem centrada na governança, em reformas institucionais e em educação cidadã acerca das vantagens das políticas propostas. A reforma do setor informal é o segundo foco de atuação, e o exemplo inspirador vem da atuação do Instituto Libertad y Democracia, no Peru. Existem razões políticas no interesse pelo setor informal, pois o CIPE avalia que ele oferece importante base para as políticas populistas. ${ }^{39} \mathrm{O}$ fortalecimento de pequenas e médias empresas é de interesse do CIPE. O terceiro foco é capacitar o setor privado a participar de forma mais ativa nos processos de definição das políticas públicas, sempre com o objetivo de criar um consenso em torno da democracia e das reformas em favor do mercado. Ao mesmo tempo, com outro foco, o CIPE seguirá apoiando a implementação da "governança corporativa e a cidadania corporativa” (corporate citizenship), como mecanismos para fortalecer o mercado de capitais e atrair investimentos. Finalmente, outro foco de atuação será o combate à corrupção, que, segundo avaliação do CIPE, representa um custo elevado para as empresas que atuam na América Latina. ${ }^{40}$

\section{CIPE E O SISTEMA FINANCEIRO}

Como mencionei na introdução deste texto, ao iniciar a pesquisa atual, parti da estrutura de representação de classe do empresariado financeiro na América Latina, manifesta na rede transassociativa das associações de bancos, e indaguei sobre as possíveis conexões que se estabeleciam com outros espaços de articulação e organização de classe. Encontrar no caminho o CIPE e, em consequência, o NED,

${ }^{39}$ Como já foi mencionado, o processo de formalização do setor, no Peru, teria contribuído para enfraquecer a esquerda naquele país, segundo avalia o ILP.

${ }^{40}$ Segundo o documento do CIPE, se estimam em $10 \%$ os custos de transação envolvidos em corrupção. alargou o horizonte da pesquisa, descortinando um universo de relações e significados bem mais amplo do que imaginava inicialmente.

Esse movimento exploratório-descritivo preliminar permite identificar algumas conexões com o sistema financeiro, e, mais especificamente, com a estrutura de classe expressa nas associações de bancos. Para efeito analítico, considerei que a interconexão entre esses níveis poderia se estabelecer diretamente, tanto por essas associações como pelas instituições financeiras, especialmente aquelas de maior centralidade na rede transassociativa.

A rede de parceiros do CIPE, uma organização atrelada aos interesses estratégicos do governo e das corporações dos Estados Unidos, não esgota o universo de organizações político-ideológicas que se vinculam ao sistema financeiro, nem sequer podemos afirmar que sejam as mais significativas. Assim mesmo, os vínculos identificados dão conta da complexa relação que se estabeleceu entre esse país e organizações internas na América Latina para construir sua hegemonia a partir de meados dos anos 80 .

Um sentido mais geral dessa conexão é dado pelo posicionamento do CIPE ao considerar o papel fundamental das associações empresariais como atores políticos fundamentais no processo de implementação das reformas políticas e econômicas voltadas para o mercado. Em outro sentido, as propostas de reformas de livre mercado coincidem com o discurso das associações do setor financeiro, embora nem sempre quando se trata de abertura do próprio setor.

Em termos mais específicos, pode-se identificar o envolvimento direto de instituições financeiras no financiamento de algumas das organizações que realizaram ou ainda mantêm "parcerias" com o CIPE. Uma primeira referência é a participação das instituições financeiras privadas, junto com outras empresas, brasileiras e multinacionais, no financiamento dos Institutos Liberais organizados no Brasil a partir de 1983, conforme foi mencionado. ${ }^{41}$ Um desses institutos, o do Rio de Ja-

${ }^{41}$ Alguns exemplos são bem emblemáticos da relação com os Institutos Liberais, como é o caso de Roberto Konder Bornhausen, do Unibanco, que ocupou a presidência de várias entidades de classe do setor. 
neiro, foi quem estabeleceu uma "parceria" direta com o CIPE.

Um segundo exemplo se refere às organizações envolvidas no programa mundial de Governança Corporativa estimulado pelo CIPE, em estreita associação com a USAID. Entre as $21 \mathrm{em}-$ presas ("associadas patrocinadoras") que contribuem diretamente para a manutenção do Instituto Brasileiro de Governança Corporativa (IBGC), oito são vinculadas ao setor financeiro. Além da Bolsa (BM\&FBOVESPA), estão três dos maiores bancos privados brasileiros (Bradesco, Itaú e Unibanco) e um estrangeiro (ABN Amro) ${ }^{42}$, que também participam da diretoria de várias associações de classe do setor financeiro. O Itaú se envolve diretamente na ampliação da cobertura jornalística sobre o tema da Governança, através do "Prêmio IBGC-Itaú Jornalismo", que, em 2008, realizou sua terceira edição, buscando estimular os jornalistas a produzirem matérias sobre o tema. ${ }^{43}$

No Chile, uma das principais fontes privadas de recursos do Centro para el Gobierno de la Empresa é o espanhol Banco Santander, um dos mais centrais na rede transassociativa. Na Argentina, o CIPE atua nesse campo com a Fundación Centro de Estabilidad Financiera (CEF), uma organização articulada durante a crise de 2001 e que passou a funcionar no ano seguinte com o objetivo de "contribuir para a análise, o debate e a formulação de políticas públicas em temas relacionados aos serviços financeiros". ${ }^{44}$ Entre os nove membros do Conselho de Administração do CEF, encontra-se o vice-presidente da Asociación de Bancos Privados de Capital Argentino (ADEBA). ${ }^{45} \mathrm{O}$

${ }^{42}$ Os demais são estatais (Banco do Brasil, Banco do Estado do Rio Grande do Sul e Nossa Caixa).

${ }^{43}$ É também uma forma de contornar a restrição estatutária do IBGC sobre a publicação de matérias pagas.

${ }^{44}$ O Mercado a Término de Rosario (ROFEX) e o Instituto Argentino de Ejecutivos de Finanzas (IAEF) são os fundadores do CEF. O site da organização não identifica explicitamente o conjunto de financiadores, que incluem além dos fundadores, fontes multilaterais e bilaterais, institutos públicos e privados além de aportes individuais. (Disponível em: http://www.cefargentina.org/ espanol/ Acesso em: 13/10/2008. Ver especialmente CEF - Memoria de Actividades 2006).

45 A ADEBA foi criada em 1972, com a denominação de Asociación de Bancos Argentinos, e reorganizada com a atual denominação em abril de 2003, por iniciativa de bancos projeto desenvolvido pelo CEF, com apoio do CIPE em 2007-2008, se relaciona com a governança corporativa entre as empresas financeiras que operam na Argentina. Situação semelhante podemos encontrar no México, onde o Centro de Excelencia en Gobierno Corporativo (CEGC) ${ }^{46}$ inclui a Asociación Mexicana de Bancos entre os sete membros de seu Conselho Consultivo Institucional. ${ }^{47}$ Na Argentina, o Instituto Argentino para el Gobierno de las Organizaciones (IAGO) foi organizado pela Fundación Empresarial para la Calidad y la Excelencia (FUNDECE) e o Instituto para el Desarrollo Empresarial (IDEA), uma organização que conta com mais de 400 empresas associadas, entre as quais bancos locais, especialmente estrangeiros, ${ }^{48}$ e associações de classe, incluindo a Asociación de Bancos de la Argentina (ABA) e a Asociación de Bancos Privados de Capital Argentino (ADEBA).

No caso argentino, bancos locais e estrangeiros se encontram entre as empresas mantenedoras da Fundación Mediterrânea ao qual o IERAL está vinculado. Entre as instituições privadas, é o Citibank que estabelece uma conexão indireta entre o CIPE e algumas associações de bancos através de sua participação simultânea na diretoria daquelas associações e na diretoria das Câmaras Americanas de Comércio em vários países da América Latina. ${ }^{49}$

Pode-se constatar que, na parceria direta

privados argentinos (http://www.adebaargentina.com.ar/ ?page=institucional).

${ }^{46}$ O CEGC foi fundado em março de 2004 pela Universidad Anáhuac del Sur e pela empresa Deloitte de México, com o apoio e assessoria da Universidade de Yale, o Banco Mundial e o NACD (National Association of Corporate Directors), uma organização vinculada aos membros dos conselhos das corporações, localizada na capital norteamericana e dedicada à questão de governança corporativa.

47 Os demais membros são: Instituto Mexicano de Ejecutivos de Finanzas, Nacional Financiera, Bolsa Mexicana de Valores, Confederación de Cámaras de la Industria, Asociación Mexicana de Intermediarios Bursátiles e o Club de Empresarios Bosques.

${ }^{48}$ Entre as dezenove instituições financeiras mencionadas como associadas, encontram-se ativos participantes das associações de classe como o Citibank, o ABN AMRO, o Banco Itaú, o Deutsche Bank e o HSBC (http:// www.ideared.org/ Acesso em: 13/10/2008).

${ }^{49}$ Em 2008, o Citibank estava presente na diretoria das Câmaras Americanas de Comércio nos seguintes países: República Dominicana, Guatemala, Peru, Equador (Quito), Uruguai, Brasil e Brasil (Rio de Janeiro). 
com as organizações de representação de classe do empresariado na América Latina, o CIPE privilegia aquelas de maior representatividade setorial, nas quais, normalmente, as associações de bancos também participam. É o caso da peruana Confederación de Instituciones y Empresas Privadas (CONFIEP), na qual participa a Asociación de Bancos de Peru (ASBANC).

\section{CONSIDERAÇÕES FINAIS}

Neste artigo, examinei aspectos particulares de um processo mais amplo de relações que se estabelecem entre organizações norte-americanas instituídas no começo dos anos 80 e sua articulação com organizações na América Latina, com o objetivo de não apenas renovar a ordem capitalista no continente, mas desenvolvê-la conforme os interesses estratégicos do governo e das corporações dos Estados Unidos. A análise das informações sintetizadas nesse artigo possibilita algumas reflexões.

Em termos gerais, as organizações norte-americanas aglutinadas em torno do NED tratam de criar e manter um consenso geral no continente em torno de um eixo fundamental: democracia e livre mercado. Quando, no final dos anos 80, as principais propostas econômicas foram definidas em torno do chamado Consenso de Washington, uma rede de entidades já estava atuando na América Latina com apoio financeiro e organizacional no sentido de formular e implementar políticas públicas convergentes com o consenso mencionado. Cabe ao CIPE atuar de forma mais direta com os interesses empresariais e as organizações a eles vinculadas, enquanto o Solidarity Center atua junto às organizações dos trabalhadores. As associações empresariais foram estimuladas a assumir um papel central na definição das políticas públicas, atuando junto aos poderes executivo e legislativo. Em seu conjunto, identificamos um processo de construção de hegemonia no sentido gramsciano do termo. Como sugere Mato (2007, p. 22), a expansão das ideias neoliberais não é simplesmente consequência das políticas econômicas impostas pelas instituições fi- nanceiras multilaterais e (ou) FMI, mas, além disso, e inclusive cronologicamente antes, a ascendência dessas ideias é o "resultado de práticas de atores sociais" que participam em redes transnacionais e que, de longa data, promovem "um sentido comum" de natureza neoliberal. A forma e o ritmo que assumiu a expansão do ideário e a implementação de políticas neoliberais estiveram condicionados pelas condições específicas de cada país, em um contexto de reestruturação econômica global (Basualdo; Arceo, 2006a; Cruz, 2004, 2007). ${ }^{50}$ A criação de um consenso em torno de reformas econômicas e políticas alcançou relativo sucesso, considerando as políticas públicas adotadas pela maioria dos países do continente ao longo das décadas de 80 e 90 e a influência que os valores capitalistas alcançaram na região. Um processo que se estabelece não sem resistências e movimentos contra-hegemônicos, que ganham força especialmente quando as implicações sociais, políticas e econômicas do modelo adotado se revelam de forma mais clara. É quando também se percebe o alcance limitado da democracia que essas organizações estão dispostas a aceitar: uma democracia que não pode contrariar o mercado, tampouco questionar os interesses estratégicos dos Estados Unidos.

Deve-se ter presente que a atuação do NED e de suas quatro organizações foi em parte desenvolvida no passado, através da Central de Inteligência Americana (CIA), como reconhecem vários autores, inclusive dirigentes do próprio NED. A atuação através de centros de pesquisa e de formulação de políticas públicas e também de ação política direta se realizou ao longo do continente para interferir nos processos políticos locais e contribuiu para desestabilizar e derrubar governos na região. ${ }^{51}$

50 Para uma análise detalhada, ver os demais trabalhos, incluindo casos nacionais, publicados na coletânea (Basualdo, Arceo, 2006). O livro de Cruz (2007) aprofunda a temática com um estudo comparativo incluindo a Índia, a Coreia do Sul e a Argentina.

51 No caso brasileiro, um exemplo significativo é o Instituto de Pesquisas Econômicas e Sociais (IPES) e seu papel no golpe de estado de 1964 e durante o primeiro governo militar (sobre esse caso, ver especialmente Dreifuss,1981). A experiência do Chile, durante o governo Salvador Allende, constitui outro caso significativo. Além disso, as ações externas norte-americanas se exerceram através de outras organizações no período anterior à formulação do NED (Cf. Dreifuss, 1986). 
A análise da atuação do CIPE deve ser realizada levando-se em conta o conjunto de ações desenvolvidas pelo NED e considerada no contexto mais amplo da política externa norte-americana. $\mathrm{O}$ NED e as quatro organizações a ele vinculadas expressam a articulação entre o Estado e as grandes corporações norte-americanas, combinada com um setor de cúpula da classe trabalhadora daquele país e os dois partidos políticos dominantes (Republicano e Democrata). Sua articulação, organização e atuação envolvem uma rede que inclui órgãos do governo dos Estados Unidos, associações empresariais, think tanks, intelectuais, universidades, centros de pesquisa e veículos da mídia, grupos econômicos e financeiros, ONGs e outras organizações da sociedade civil nos Estados Unidos e na América Latina. Além disso, como foi possível perceber, instituições do Grupo Banco Mundial (o próprio Banco e o IFC) e o BID se integram a essa estratégia, pois se constatou que algumas organizações "parceiras" do CIPE também recebem fundos dessas instituições. Dessa forma, a atuação do Banco Mundial e do BID não se realiza apenas na dimensão macroeconômica e de forma direta com os governos, mas também reforça essa extensa rede de ação em favor de reformas políticas e de livre mercado, de acordo com os interesses hegemônicos dos Estados Unidos. Escapa ao alcance deste artigo, mas é necessário ter presente que, no período, além da estratégia política e ideológica - em parte descrita neste trabalho -, os Estados Unidos mantiveram uma ativa estratégia militar e, na década de 90, ampliaram acordos e bases militares, estendendo sua presença militar à Europa Central e a mais de cem países ao redor do globo (Petras, 1997; Fiori, 2004).

Na América Latina, atuam também outras organizações que não se vinculam diretamente aos interesses estratégicos dos Estados Unidos, mantendo com eles campos de articulação, mas também de concorrência. Algumas delas estão vinculadas a partidos políticos europeus. Outras são controladas por instituições privadas e jogam um papel fundamental na promoção das ideias neoliberais em escala mundial, como o Institute of Economic Affairs (IEA) e Atlas Economic Research
Foundation (Gros, 2003)..$^{52}$ Mato (2007) identificou dezesseis organizações latino-americanas que receberam recursos dessa fundação, algumas delas também apoiadas pelo CIPE. ${ }^{53}$ Outra rede orientada especialmente para a América Latina é mantida pela Fundación Internacional para la Libertad (FIL), presidida pelo escritor Mario Vargas Llosa. ${ }^{54} \mathrm{Al}-$ guns países criaram organizações similares para sua atuação no exterior, como o Canadá com seu International Center for Human Rights and Democratic Development (ICHRDD), organizado em $1990 .{ }^{55}$ No âmbito da ONU, especialmente a partir de 1993, os Estados Unidos se defrontaram com diferentes concepções e propostas de atuação na promoção da democracia (Pubantz, 2007).

O fato de realizar parcerias com o CIPE não significa que as organizações passem a depender necessariamente da organização norte-americana. As parcerias se fazem em um contexto de convergência de interesses do ponto de vista da manutenção e renovação de uma ordem capitalista, mas o papel que as organizações podem desempenhar nesse processo pode sofrer variações importantes. Como já foi mencionado, as organizações locais operam também com diferentes fontes de financiamento. A estratégia do CIPE é de longo prazo, mas operacionaliza suas ações através projetos específicos de apoio organizacional, político e financeiro com objetivos e prazos definidos. Esse procedimento lhe permite operar com grande flexibilidade para manter, redefinir ou romper as parcerias, em função dos resultados alcançados ou de alterações

52 Os dois últimos foram criados por Anthony Fisher, seguidor das ideias de Hayek. O IEA está localizado na Inglaterra e Atlas nos Estados Unidos. Em 2001, a Atlas Economic Research Foundation da Inglaterra, também fundada por Anthony Fisher, se transformou em uma instituição chamada The International Policy Network (Mato, 2007, p.68).

${ }^{53}$ Por exemplo, o Instituto Libertad y Democracia no Peru e o Centro de Divulgación del Conocimiento Econômico (CEDICE) na Venezuela (Mato, 2007, p.30).

${ }^{54}$ Segundo Mato (2007, p.33), a FIL conta com uma complexa estrutura de comando, que inclui representantes de instituições da América Latina, Europa e Estados Unidos.

${ }^{55}$ Scott e Walters (2000) desenvolvem um estudo comparativo entre o NED, e o International Center for Human Rights and Democratic Development (ICHRDD) e a Westminster Foundation for Democracy (WFD) estabelecida pelo governo da Inglaterra em 1992. Abelson (2000) compara think tanks do Canadá e dos Estados Unidos. 
conjunturais em cada país, ou ainda em razão das suas prioridades, que são definidas em termos de sua atuação global. Como observa Cruz (2007, p.41), para analisar a política do neoliberalismo “... é preciso ver como os grupos ou tendências políticas identificados com essa perspectiva atuam, que problemas enfrentam, que alianças precisam estabelecer para se colocar em posição de implementar os seus projetos".

O sistema financeiro vincula-se, de diversas formas, à rede de organizações mencionada. Como se viu, instituições financeiras multilaterais, como o Banco Mundial e o BID, apoiam algumas dessas organizações. Associações de representação de classe do setor financeiro participam de associações empresariais que também recebem recursos do CIPE. Instituições financeiras privadas, especialmente grupos financeiros, participam e aportam recursos. O Citigroup, por exemplo, tem uma presença ativa nas associações de bancos na América Latina, assim como nas Câmaras Americanas de Comércio existentes no continente. Sobretudo, é necessário destacar que o sistema financeiro, na América Latina, em ritmos e graus diversos de intensidade, sofreu um profundo processo de abertura e desregulamentação, assim como foi alvo de privatização, políticas que o NED e especialmente o CIPE apoiaram e contribuíram para estabelecer.

O modelo de democracia institucional que os Estados Unidos pretendem exportar para o mundo, além de essencialmente articulada com a economia de livre mercado, busca gerar posições aliadas ou amistosas com os interesses políticos e econômicos dos Estados Unidos. Não se trata de implementar, manter e renovar uma ordem democrática e capitalista em cada país apenas; ela deve articular-se com os interesses estratégicos da potência hegemônica. Dessa forma, o campo dessa disputa democrática cria alianças e também rivalidades com as iniciativas de outros países capitalistas que também desenvolvem ações semelhantes através de organizações específicas. Ao mesmo tempo, não consegue ocultar as contradições com práticas internas e, especialmente, externas de atuação. As debilidades também se revelam quando se deparam com processos locais que questionam a economia de livre mercado e os interesses dos Estados Unidos, ou se conectam com movimentos populares, como está ocorrendo atualmente em alguns países da América Latina. Que o modelo de democracia e o esforço do governo e das corporações norte-americanas para implementá-lo ao redor do mundo seja eivado de contradições não deixa de colocar um significativo desafio teórico e político em torno da questão da democracia, ${ }^{56}$ além de levantar novas questões relacionadas com o imperialismo. ${ }^{57}$

A partir da rede de organizações que se inseriram na estratégia do governo e das corporações norte-americanas e das práticas que dela derivam e as forças sociais e políticas que logram mobilizar a partir de meados dos anos 80, é possível perceber uma estrutura complexa e abrangente de relações. Mesmo que não tenham conseguido evitar as contradições geradas pela implementação, em maior ou menor grau, das políticas neoliberais, definiram e estruturaram um padrão de atuação e de luta de classes cuja melhor compreensão ainda deve ser alcançada.

(Recebido para publicação em dezembro de 2008) (Aceito em março de 2009)

\section{REFERÊNCIAS}

ABELSON, Donald E. Do think tanks matter? Opportunities, constraints and incentives for think tanks in Canada and the United States. Global Society, New Jersey, v. 14, n. 2, p. 213-236, 2000.

AMORIM, Wilson Aparecido Costa de. A evolução das organizacões de apoio às entidades sindicais brasileiras-: um estudo sob a lente da aprendizagem organizacional 2007. 430f. Tese (Doutorado) - Universidade de São Paulo. 2007.

${ }^{56}$ Ver, por exemplo, Boron (2006), Chomsky (2007), especialmente capítulo 4 "Fomento de la democracia en el extranjero"). Guilhot (2001) faz uma análise da cooptação de intelectuais para esse processo de defesa de uma democracia conforme à visão e ao interesse do governo e das corporações norte-americanas. Callari (2008) considera que essa cruzada pela democracia se vincula à nova forma do imperialismo e requer das forças políticas da esquerda e do discurso marxista o engajamento no terreno do debate sobre democracia.

${ }^{57}$ Ver, por exemplo, Panitch e Leys (2006, 2006a), Slater (2006), Petras (1999). 
BASUALDO, Eduardo; ARCEO, Enrique (Org.) Neoliberalismo y sectores dominantes: tendências globales y experiencias nacionales. Buenos Aires: CLACSO, 2006.

Los cambios de los sectores dominantes em América Latina bajo el neoliberalismo. In: _ (Org.) Neoliberalismo y sectores dominantes: tendências globales y experiencias nacionales. Buenos Aires: CLACSO, 2006a. p. 15-26.

BOHN, John. CIPE at 15 years: Lessons learned. In: GEURTS, Geoffrey; ROGERS, Steven; SULLIVAN, John D. Impact and results of CIPE's global programs, 19841999. Washington, DC: Center for International Private Enterprise, 2001. p. 9-19.

BORON, Atilio A. Crisis de las democracias y movimientos sociales en América Latina: notas para una discusión. OSA: Observatorio Social de América Latina, Buenos Aires, CLACSO, v. 7, n. 20, mayo/ag., 2006. Disponível em: http:/ /bibliotecavirtual.clacso. org.ar/ar/libros/osal20/boron.pdf. Acesso: 05 jun. 2008.

BRAUN, Miguel; CICIONI, Antonio; DUCOTE, Nicolas J. Think tanks in developing countries: lessons from Argentina. In: STONE, Diane; DEHAM, Andrew (Ed.) Think tank traditions: -policy research and the politics of ideas. Mancheste: University Press, 2004. Disponível em: http:/ /books.google.com/books

CALLARI, Antonio. Imperialism and the rhetoric of democracy in the age of Wall Street. Rethinking Marxism, [S.l.], v. 20, n. 4, p.700-709, oct., 2008.

CHOMSKY, Noam. Estados fallidos: el abuso de poder y el ataque a la democracia. Buenos Aires: Ediciones Grupo Zeta, 2007.

CIPE. Annual Report 2000 a 2007. Washington, DC, Disponíveis em: http://www.cipe. org/publications/report/ archives/. Acesso em: sept./oct. 2008.

Five year strategy 2007-2012. Center for International Private Enterprise, February 2007. Washington, DC, Disponível em: http://www.cipe.org/about/ strategy5year.pdf. Acesso em: 25 apr. 2008.

Guía para la Agenda Nacional Empresarial. La Voz de las empresas. Washington,DC, 32p. Disponível em: http://www.cipe.org/regional/lac/pdf/spanishnba. pdf Acesso em: 05 sept. 2008.

Global Partners 1984-2003. Washington, DC Disponível em: http://www.cipe. org/publications/report/ archives/2003/Financials.pdf

CIPPEC. Newsletter 26 Oct., 2006. -Disponível em: http:/ /cippec.org/espanol/newsletter/n26/Proyecto_1.htm. Acesso em: 29 sept. 2008

CRUZ, Sebastião C.Velasco e. Argumentos sobre as "reformas para o mercado"- nos países em desenvolvimento. In: Globalização, democracia e ordem internacionat: ensaios de teoria e história. Campinas, SP: Ed.UNICAMP; Ed. UNESP, 2004. p. 91-115.

Trajetórias: capitalismo neoliberal e reformas econômicas nos países da periferia. São Paulo: Ed. UNESP/ Programa San Tiago Dantas de Pós-Graduação em Relações Internacionais da UNESP; Unicamp; PUC-SP, 2007.

DREIFUSS, René Armand. 1964: a conquista do Estado: ação política, poder e golpe de classe. 3.ed. Petrópolis: Vozes, 1981.

A internacional capitalista. Estratégias e táticas do empresariado transnacional 1918-1986. Rio de Janeiro: Editora Espaço e Tempo, 1986.

FIORI, José Luís. O poder global dos Estados Unidos: formação, expansão e limites. In: (Org.) $O$ poder americano. Petrópolis: Vozes, 2004. p.67-109.
GEURTS, Geoffrey; ROGERS, Steven; SULLIVAN, John D. Impact and results of CIPE's global programs, 1984 1999. Washington,DC, CIPE - Center for International Private Enterprise, August 2001.

GOLINGER, Eva. El código Chávez. Descifrando la intervención de los Estados Unidos em Venezuela. La Habana, Cuba: Editorial de Ciencias Sociales, 2005.

. Bush vs. Chávez. La guerra de Washington contra Venezuela. La Habana, Cuba: Editorial José Martí, 2006.

GROS, Denise Barbosa. Institutos Liberais e Neoliberalismo no Brasil da Nova República. Porto Alegre: Fundação de Economia e Estatística Siegfried Emanuel Heuser, 2003. (Teses FEE, 6).

GROS, Denise B. Institutos Liberais, Neoliberalismo e políticas públicas na Nova República. Revista Brasileira de Ciências Sociais, São Paulo, ANPOCS, v. 19, n. 54, fev., p. 143-159, 2004

GUILHOT, Nicolas. Les professionnels de la démocratie. Logiques militantes et logiques savantes dans le nouvel internationalisme américain. Actes de la Recherche em Sciences Sociales, Paris, n.139, p. 53-65, 2001-2003, Disponível em: http://www.cairn.info/ article.php?id_revue= arss\&id_numpublie $=$ arss_139\&id_article $=$ arss_139_0053. Acesso em: 14 août. $200 \overline{8}$.

HARVEY, David. O Neoliberalismo. História e implicacões. Trad. Adail Sobral e Maria Stela Gonçalves. São Paulo: Edições Loyola, 2008

HALE, Eric T. A quantitative and qualitative evaluation of the National Endowment for Democracy, 1990-1999. 2003. 304f. These (Doctor of Philosophy) - Department of Political Science, Louisiana State University, Disponível em: http: /etd.lsu.edu/docs/ available/etd-1105103-140728/ unrestricted/Hale_dis.pdf. Acesso em: 30 oct. 2008.

IERAL. Instituto de Estudios de la Realidad Argentina y Latinoamericana. Orígenes y objetivos. Disponível em: http://www.ieral.org/. Acesso em: 25 sep. 2005.

ISLAM, Nafisul. Making the 'extralegal' legal. In: CIPE. Strategies for policy reform: experiences from around the world. Washington,Dc, 2007. p. 54-58.

LOWE, David. Idea to reality: A brief history of the National Endowment for Democracy. Disponível em: http:// www.ned.org/about/nedhistory.html Acesso em: 12 may 2008.

MASHEK, Robert W. Performance and prospects for Legislative Advisory Programs in Latin América. A report on 11 national and one regional Legislative Advisory Programs in Latin America, submitted to the Center for International Private Enterprise (CIPE), march n. 15, p. 59-106, 1993. Disponível em: http://www.cipe.org/ programs/evaluations/pdf/ aplac_evaluation.pdf. Acesso em: 30 aug. 2008.

MATO, Daniel. Cultura, comunicación y transformaciones sociales en tiempos de globalización. In:

MALDONADO FERMÍN, Alejandro (Comp.) Cultura y transformaciones sociales en tiempos de globalización. Perspectivas latinoamericanas. Buenos Aires: CLACSO, 2007. Disponível em: http://bibliotecavirtual.clacso.org.ar/ ar/ libros/campus/mato/Alvear C.pdf. Acesso em: 06 oct. 2008.

MATO, Daniel. Think Tanks, fundaciones y profesionales en la promoción de ideas (neo)liberales en América Latina. In: GRIMSON, Alejandro. Cultura y neoliberalismo. Buenos Aires: CLACSO, 2007a. Disponible em: http:// bibliotecavirtual.clacso.org.ar/ar/libros/grupos/grim_cult/ Mato.pdf

MILNER, Larry S. (Ed.) Business Associations for the 21st Century. A blueprint for the future. 2.ed. Washington Center for International Private Enterprise (CIPE), 1999. 
MINELLA, Ary Cesar. Representação de classe do empresariado financeiro na América Latina: a rede transassociativa no ano 2006. Revista de Sociologia e Política, Curitiba, UFPR, n.28, p.31-56, jun. 2007. Disponível em: http://www.scielo.br/pdf/rsocp/n28/ a04n28.pdf, http://socialsciences.scielo.org/pdf/s_rsocp/v3nse/ scs_a03.pdf (versão em inglês).

OLIVEIRA, Francisco de. A dominação globalizada: estrutura e dinâmica da dominacão burguesa no Brasil. In BASUALDO, Eduardo; ÅREO, Enrique (Org.) Neoliberalismo y sectores dominantes: tendencias globales y experiencias nacionales. Buenos Aires: CLACSO, 2006. p. 265-291.

NED. Latin America and the Caribbean Program (2000 2007). Disponíveis em: http://www.ned.org/grants/. Acesso em 30 oct., 2008.

OSPINA, Hernando C. A mão (quase) invisível de Washington. Le Monde Diplomatique, Brasil, São Paulo, jul. 2007. Disponível em: http://diplo.uol.com.br/imprima1726 Acesso em: 7/8/2007.

PANITCH, Leo; LEYS, Colin (Org.) Socialist register 2004 o novo desafio imperial. Buenos Aires: CLACSO, 2006.

(Org.) Socialist register 2005: o império reloaded Buenos Aires: CLACSO, 2006a.

PAYNE, Douglas W. A Latin Last Hurrah. Society, New York, v. 27, n. 2, p. 41-52, jan. 1990.

PETRAS, James. Imperialism and NGOs in Latin America, Monthly Review, [S.1.], v.49, n.7, dec., 1997. Disponível em: http://www.monthlyreview.org/1297petr.htm Acesso em: 10 aug. 2008 .

. NGOs: In the service of imperialism. Journal of Contemporary Asia, [S.1.], v. 29, n. 4, p. 429-440, 1999.
Disponível em: http://hmb.utoronto.ca/HMB303H/ weekly supp/ week-12-13/Petras NGOsImperialism.pdf. Acesso em: 12 aug. 2008.

Os fundamentos do neoliberalismo. In: RAMPINELLI, Waldir J.; OURIQUES, Nildo (Org.) No fio da navalha: critica das reformas neoliberais de FHC. São Paulo: Xamã, 1997. p. 15-38.

POWELL, Lewis F Confidential Memorandum to Eugene B. Sydnor, U.S. Chamber of Commerce. Aug., 23, 1971. Disponível em: http://www.reclaimdemocracy.org/ corporate_accountability/powell_memo_lewis.html. Acesso: 31 oct. 2008.

PUBANTZ, Jerry. The US-UN relationship and the promotion of Democratic Nation-Building. Societies Without Borders, [S.1.], n. 2, p. 93--116, 2007. Disponível em: www.brill.nl/swb. Acesso: 26 sept. 2008.

RAMÍREZ, Hernán. Institutos de estudos econômicos de organizações empresariais e sua relacão com o Estado em perspectiva comparada: Argentina e Brasil, 1961-1996. Anos 90 Porto Alegre, UFRGS, v. 13, p. 179-214, 2006. Disponível em: http://www.ufrgs.br/ ppghist/2324Art10.pdf Acesso em: 09 out., 2008

La Fundación Mediterránea y de cómo construir poder. La génesis de un provecto hegemónico. Córdoba: Ferreyra Editor, 2000.

SCOTT, James M.; WALTERS, Kelly J. Supporting the wave: western political foundations and the promotion of a global democratic society.- Global Society, New Jersy, v. 14 , n. 2, p. 237-257, 2000

SLATER, David. Imperial powers and democratic imaginations. Third World Quarterly, New York, v. 27, n. 8, p. 1369-1386, 2006 
Ary Cesar Minella

Quadro 4 - América Latina e Caribe. Organizaçōes parceiras do CIPE (1984-2007)

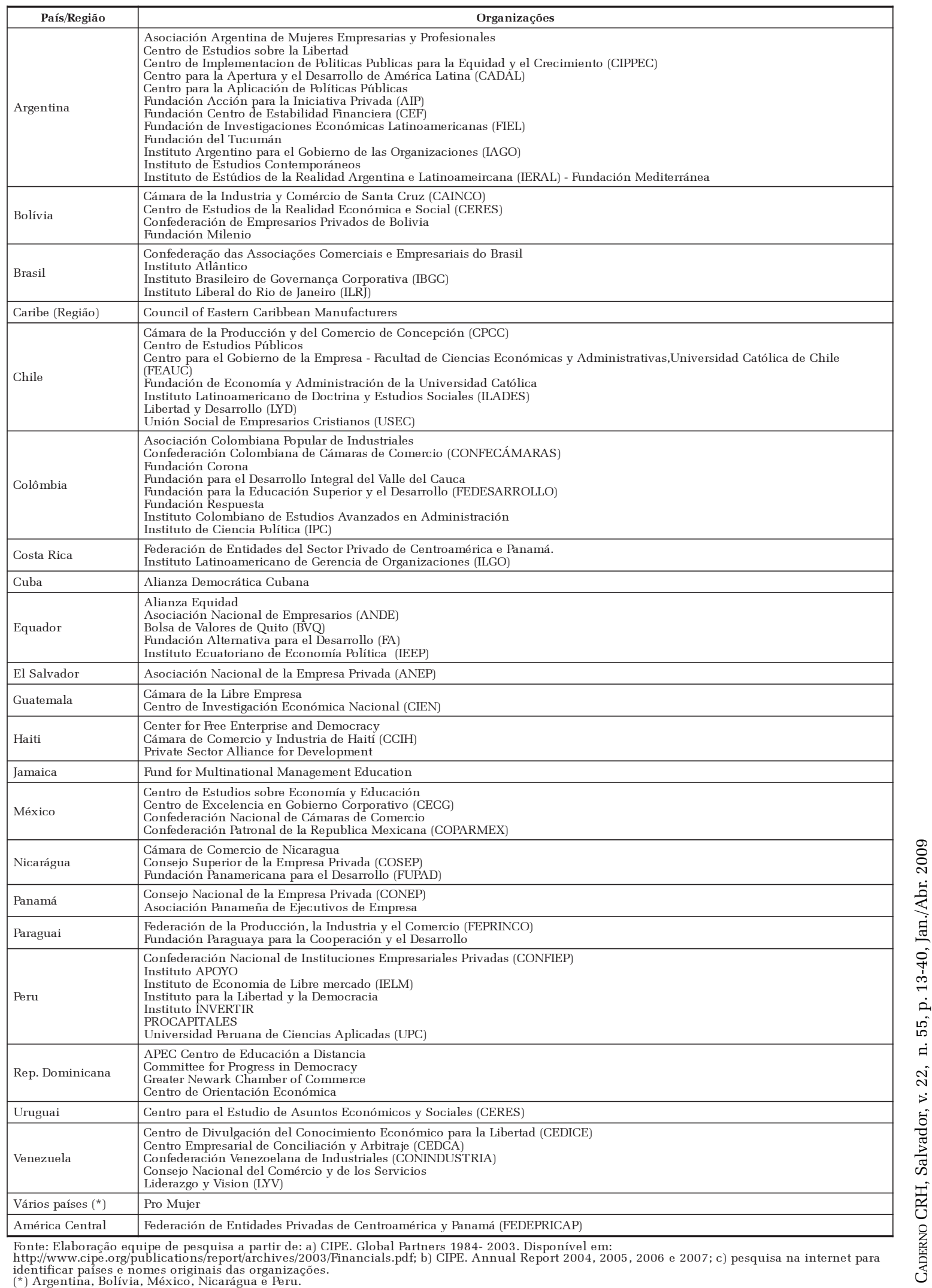


Tabela 6 - NED. Parcerias no Peru (2000-2007)

Valores em US\$

\begin{tabular}{|c|c|c|c|c|c|c|c|c|c|}
\hline Organizaçốes/ano & 2000 & 2001 & 2002 & 2003 & 2004 & 2005 & 2006 & 2007 & TOTAL \\
\hline TOTAL & 570.000 & 276.946 & 492.999 & 822.275 & 635.390 & 638.979 & 821.644 & 1.305 .508 & 5.563 .741 \\
\hline Partidos Políticos (Através do IRI) & & & 299.999 & 324.999 & 300.000 & 300.000 & 350.000 & 400.000 & 1.974 .998 \\
\hline Partidos Políticos (Através do NDI) & & & & 74.001 & 72.863 & & & 366.980 & 513.844 \\
\hline Foro Democratico (Através do IRI) & 380.000 & & & & & & & & 380.000 \\
\hline Instituto de Estudios Estratégicos y Políticos & 65.000 & 78.000 & 89.000 & 70.000 & 75.017 & & & & 377.017 \\
\hline Instituto APOYO (2006 em associação com CONFIEP). & & 87.946 & & 143.410 & & & 115.481 & & 346.837 \\
\hline Consejo de la Prensa Peruana & & & & 50.000 & 61.850 & 66.830 & 70.000 & 70.000 & 318.680 \\
\hline Instituto de Defensa Legal & 50.000 & 56.000 & 59.000 & 59.265 & & & & 55.906 & 280.171 \\
\hline Comision Andina de Juristas & & 30.000 & 45.000 & 60.600 & 60.660 & 76.477 & 4.132 & & 276.869 \\
\hline Consejo Nacional para la Ética Pública-Proética & & & & 40.000 & 40.000 & 56.560 & 56.645 & 59.090 & 252.295 \\
\hline Consorcio de Investigación Económica y Social (CIES) & & & & & & 49.880 & 24.016 & 47.900 & 121.796 \\
\hline Centro de Capacitación J.M. Arguedianos & & & & & 25.000 & 30.000 & 30.000 & 30.000 & 115.000 \\
\hline Instituto de Prensa y Sociedad & 75.000 & 25.000 & & & & & & & 100.000 \\
\hline Asociación de Jueces para la Justicia y Democracia del Perú & & & & & & & 40.000 & 50.000 & 90.000 \\
\hline Asociación Negra de Defensa y Promoción de los Derechos Humanos & & & & & & & 30.000 & 40.000 & 70.000 \\
\hline Governança Corporativa (Conferências) (Através do CIPE) & & & & & & 59.232 & & & 59.232 \\
\hline Foro Nacional/Internacional & & & & & & & 46.700 & 9.500 & 56.200 \\
\hline Ciudadanos al Día & & & & & & & 54.670 & & 54.670 \\
\hline Socios Peru - Centro de Colaboración Cívica & & & & & & & & 39.900 & 39.900 \\
\hline Ciudad Nuestra & & & & & & & & 39.713 & 39.713 \\
\hline Comisión Diocesana de Servicio Pastoral Social & & & & & & & & 36.495 & 36.495 \\
\hline Comisión de Solidaridad. Desarrollo y Justicia & & & & & & & & 34.994 & 34.994 \\
\hline Consultores en Planificación & & & & & & & & 25.030 & 25.030 \\
\hline
\end{tabular}

Fonte: Elaboração própria a partir dos Relatórios do NED. disponíveis em http://www.ned.org/grants

Obs: Não inclui programas regionais do NED 
Ary Cesar Minella

Tabela 7 - NED. Parcerias e recursos (diretos ou através do IRI e do CIPE) na Argentina (2002-2007)

\begin{tabular}{l|r|r|r|r|r|r|r}
\hline \multicolumn{1}{c|}{ Parceiro Local/ ano } & \multicolumn{1}{c|}{$\mathbf{2 0 0 2}$} & \multicolumn{1}{c|}{$\mathbf{2 0 0 3}$} & \multicolumn{1}{c|}{$\mathbf{2 0 0 4}$} & \multicolumn{1}{c|}{$\mathbf{2 0 0 5}$} & \multicolumn{1}{c|}{$\mathbf{2 0 0 6}$} & \multicolumn{1}{c}{$\mathbf{2 0 0 7}$} & \multicolumn{1}{c}{ TOTAL } \\
\hline TOTAL & 113.132 & 442.616 & 584.592 & 574.557 & 216.528 & 543.370 & 2.462 .768 \\
\hline CIPPEC & $111.130 \mathrm{a}$ & $300.000 \mathrm{~b}$ & $\begin{array}{r}100.912 \mathrm{a} \\
89.276 \mathrm{a}\end{array}$ & $\begin{array}{r}225.000 \mathrm{~b} \\
50.913 \mathrm{C}\end{array}$ & $41.328 \mathrm{c}$ & & 918.559 \\
\hline Poder Ciudadano & & & 85.000 & 79.795 & 79.018 & 80.000 & 323.813 \\
\hline Fund. Nueva Generación Argentina & & 31.613 & 46.804 & 61.561 & 66.366 & 72.027 & 278.371 \\
\hline Asociación por los Derechos Civiles & & 57.000 & 64.872 & 61.187 & & 64.445 & 247.504 \\
\hline $\begin{array}{l}\text { Fund. Centro de Estabilidad Financiera } \\
\text { (CEF) }\end{array}$ & & & & 99.785 & & 143.801 & 243.586 \\
\hline Centro de Estudios Legales y Sociales & & 52.000 & 60.000 & 71.460 & & & 183.460 \\
\hline $\begin{array}{l}\text { Asociación Civil por la Igualdad y la } \\
\text { Justicia }\end{array}$ & & & & 58.575 & & 55.050 & 113.625 \\
\hline Fund.Cambio Democrático & & & & & & 38.505 & 38.505 \\
\hline El Ágora & & & & & & 30.000 & 30.000 \\
\hline Ejercicio Ciudadano & & & & & & 29.885 & 29.885 \\
\hline Foro de Periodismo Argentino & & & & & 27.810 & & 27.810 \\
\hline $\begin{array}{l}\text { Fund. Familiares de Víctimas } \\
\text { Indefensas/Mendonza }\end{array}$ & & & & & & 27.650 & 27.650 \\
\hline
\end{tabular}

Fonte: Elaboração própria, a partir de Relatórios do NED disponíveis em <http://www.ned.org/grants/

Obs: a) através do CIPE; b) através do IRI; c) NED diretamente.

Não inclui recursos repassados através de Projetos Regionais do NED. 


\section{BUILDING HEGEMONY: DEMOCRACY AND FREE MARKET (performance of NED and of CIPE in Latin America)}

\author{
Ary Cesar Minella
}

Beginning from the verification of the existence of connections between the banking class representation associations of Latin America, the socalled transassociative network, this paper analyzes the connection of that network with American-based organizations to act politically around the world. Its main focus is the Center for International Private Interprise (CIPE), begun in 1983, linked to the United States Chamber of Commerce, and that promotes economical and political market-oriented reforms. It is one of four main organizations in the National Endowement for Democracy (NED), entity financed by the that country's government. The case of Argentina and Peru is especially examined. Two factors are examined: how the relationship of those entities with Latin-American organizations constitutes a structural base for the process of neoliberal hegemony construction and how it works with the financial system. The methodological procedure includes the bibliographical and documental research.

KEYworDs: hegemony, democracy, financial system, transassociative nets, National Endowement for Democracy (NED), Center for International Private Interprise (CIPE).

\section{L'HÉGÉMONIE EN CONSTRUCTION: DÉMOCRATIE ET LIBRE ÉCHANGE ( Le rôle du NED et du CIPE en Amérique Latine)}

\author{
Ary Cesar Minella
}

C'est à partir de la constatation de liens existants entre les associations de représentation de classe des banques en Amérique Latine, appelé réseau trans-associatif, que ce travail analyse la connexion qu'a ce réseau avec des organisations constituées aux Etats-Unis pour agir politiquement dans le monde entier. L'attention est portée sur le Center for International Private Interprise (CIPE), fondé en 1983, lié à la Chambre de Commerce des EtatsUnis, et dont les réformes politiques et économiques sont tournées vers le marché. C'estl'une des quatre organisations centrales du National Endowement for Democracy (NED), entitéfinancée par le gouvernement américain. On y étudie tout spécialement le cas de l'Argentine et du Pérou. On peut voir combien la relation de ces entités avec des organisations latino-américaines constitue une base structurale dans le processus de construction de l'hégémonie à caractère néo-libéral et comment elle s'articule avec le système financier. La méthodologie comprend une recherche bibliographique et documentaire.

Mots-CLÉs: hégémonie, démocratie, système financier, réseaux trans-associatifs, National Endowement for Democracy (NED), Center for International Private Interprise (CIPE).

Ary Cesar Minella - Doutor em Estudos Latino-americanos pela Universidad Nacional Autónoma de México. Mestre em Sociologia pela Universidade Federal do Rio Grande do Sul. Pós-Doutor em Ciência Política pela Universidade de Campinas e em Sociologia pela Universidade de São Paulo, incluindo estágio na Universidad Autónoma de Barcelona. Professor titular da Universidade Federal de Santa Catarina, Departamento de Sociologia e Ciência Política e Programa de Pós-Graduação em Sociologia Política. Tem experiência na área de Sociologia Política e Sociologia Econômica, com ênfase em Classes Sociais e Grupos de Interesse, atuando principalmente nos seguintes temas: organização corporativa e política do empresariado financeiro no Brasil e na América Latina, sistema financeiro no Brasil, grupos econômicos, redes financeiras, globalização financeira. Coordena o Núcleo de Estudos Sociopolíticos do Sistema Financeiro (NESFI), grupo de pesquisa credenciado pelo CNPq. Bolsista de Produtividade em Pesquisa do CNPq - Nível 2. Principais publicações incluem o livro Banqueiros: organização e poder político no Brasil. Os artigos mais recentes foram publicados na revista Sociologias (Maiores bancos privados no Brasil: um perfil econômico e sociopolítico), n. 18, p. 100125, jul./dez., 2007, e Revista de Sociologia e Política (Representação de classe do empresariado financeiro na América Latina: a rede transassociativa no ano 2006). n. 28, p. 31-56, jun., 2007. 